\title{
Analysis of Structural Response of Subway Shield Tunnel Lining under the Influence of Cavities
}

\author{
Yufeng Shi, ${ }^{1,2}$ Zhaoyang Chen $\mathbb{D}^{1,2}$ Duqiang Wei, ${ }^{3}$ Tao Zhang, ${ }^{1,2}$ Xuming Zhou, ${ }^{1,2}$ \\ Xiushao Zhao, ${ }^{1,2}$ Junhao $\mathrm{Hu}^{1,2}$ and Yuhang Zhou ${ }^{1,2}$ \\ ${ }^{1}$ East China Jiaotong University, Nanchang 330013, China \\ ${ }^{2}$ State Key Laboratory of Performance Monitoring Protecting of Rail Transit Infrastructure, East China Jiaotong University, \\ Nanchang 330013, China \\ ${ }^{3}$ China Railway Nanchang Group Co., Ltd., Nanchang, Jiangxi Province 330013, China
}

Correspondence should be addressed to Zhaoyang Chen; chen18256998418@163.com

Received 25 July 2021; Revised 1 November 2021; Accepted 7 December 2021; Published 29 December 2021

Academic Editor: Paolo S. Valvo

Copyright (c) 2021 Yufeng Shi et al. This is an open access article distributed under the Creative Commons Attribution License, which permits unrestricted use, distribution, and reproduction in any medium, provided the original work is properly cited.

\begin{abstract}
The existence of cavities behind the shield tunnel lining can cause cracking, broken pieces, water leakage, and other problems, which reduces the durability and safety of the shield tunnel segment structure. In order to clarify the mechanism of cavity damage, a more systematic study of the effects of cavities on the shield tunnel lining structure from the angle, depth, and the number of cavities is carried out using model tests and numerical simulations without considering the effects of the stiffness reduction effect at the tunnel segment joints and groundwater seepage in this paper. The findings show that the bending moment value and the cavity angle value are approximately linear with the increase of single cavity angle, and the bending moment at the vault arch is reversed when the angle of the cavity behind the arch is greater than $30^{\circ}$. With the increase of single cavity depth, the axial force and bending moment at the cavity increase, and the distribution of bending moment remains unchanged, and the bending moment tends to be stable and unchanged beyond a certain depth. With the increase of single cavity angle and depth, the structural safety coefficient of the segment decreases, and the degree of influence is angle value $>$ depth value. The existence of multiple cavities intensifies the influence of each cavity on the segment, especially when there are cavities behind the top and bottom of the vault; the bending moment value of the top of the vault increases by $22.53 \%$ compared with that of the single cavity condition.
\end{abstract}

\section{Introduction}

With the gradual promotion of urbanization, in order to alleviate the problem of urban traffic congestion, all large and medium-sized cities have started to vigorously develop urban rail transit, and the shield method has become one of the mainstream methods for urban rail transit tunnel construction with its construction efficiency and safety. However, due to factors such as shield overexcavation, insufficient grouting pressure, slurry solidification shrinkage, and groundwater seepage during the construction of shield method, the phenomenon of the void behind the tunnel lining is easy to occur, forming a cavity, which in turn affects the interaction between the lining and the surrounding rock.
The cavity behind the lining will easily lead to a stress concentration effect in the lining structure, which will lead to cracking, broken pieces, water leakage, and other problems, reducing the durability and safety of the shield tunnel segment structure. Therefore, it is of great significance to analyze the mechanical effects of the void behind the tunnel lining on the tunnel structure.

At present, the research on the problem of the cavity behind the lining mainly includes field flaw detection, model test, and numerical analysis. In terms of field flaw detection, Dingli et al. [1-3] concluded that the cavity behind the lining wall was more common through flaw detection in several existing tunnel projects, where the largest proportion of cavities were behind the tunnel vault and arch shoulder, 
followed by the arch waist and sidewall locations. Friebel et al. [4] concluded that tunnel cavities were mainly caused by unevenness at the excavation profile during blasting construction of the tunnel. In terms of model test, Feng et al. [5] carried out similar model tests for conditions such as noncavity behind the road tunnel lining, single cavity, and multiple cavities, and the analysis results showed that the presence of cavities leads to a reduction in the tunnel axial force and bending moment values at the corresponding cross section and an increase in the eccentricity of the tunnel structure, which in turn leads to lining breakage and cracking. MAMeguid [6] and CLeung et al. [7] investigated the effect of voids on the ground pressure loads acting on the shield tunnel lining structure through indoor model tests. Shuhong et al. [8] carried out a study on the effects of cavities at different locations behind the tunnel wall on the safety of the lining structure, respectively, through indoor model tests and analyzed the sequence and form of cracking damage to the tunnel lining structure under different working conditions. Shimin [9] and others studied the influence of the location and size of the cavity behind the shield tunnel on the internal force of the lining through model tests. In terms of numerical analysis, Yufeng et al. $[10,11]$ conducted a more comprehensive study on the problems of the cavity behind the hydraulic tunnel wall and the weakening of the connection between the invert arch and the sidewall, considering the influence law of the internal force of the lining structure under the coupling effect of different internal water pressure and cavity defects. Jian [12] and Zhen et al. [13] used the elastoplastic finite element method to simulate the effect of cavities at different locations behind the tunnel lining on the safety of the tunnel structure in mountain tunnels and concluded that the existence of cavities led to tensile stresses at the corresponding cross-sectional locations of the tunnel, which were prone to cracking, breakage, and other diseases. Deng et al. [14] analyzed the effect of particle size on the shear strength, and the stress-dilatancy behavior of sands was assessed through a series of drained triaxial compression tests on dense uniform silica sands. Tingsheng Zhao et al. [15] considered the discontinuity of shield tunnel lining and the interaction between the tunnel segments, the grouting layer, and the surrounding rock and constructed a hybrid model of the shield tunnel based on the 3D nonlinear contact theory. Wu Dangzhong et al. [16] investigated the ground deformation characteristics induced by mechanized shield twin tunneling along curved alignments by adopting the nonlinear three-dimensional (3D) finite element method (FEM) and discussed the technologies for reducing the overexcavation and improving the accuracy of tunnel lining segment installation. Mohammad Reza Majedi et al. [17] introduced a micromechanical model in which the contact bond strength is allowed to vary in proportion to the relative velocity of the involved particles and found that the modified model could reproduce the physical tests data reported in the literature. Rouhanifar Salman et al. [18] studied the strength and deformation behavior of sand rubber mixtures by using the loose specimens with a void ratio of 0.86 , corresponding to a relative density of $30 \%$ for the pure sand, and normal stresses of 50 ,
100 , and $150 \mathrm{kPa}$. Xue Li et al. [19] measured and analyzed the Earth pressure and water pressure on the tunnel lining of four cross-sections of a metro tunnel, then compared with the theoretical values, and found that the values and distribution of observed ground pressure acting on the lining are different for different overburden depths. Mingfeng Lei et al. [20] proposed a heterogeneous equivalent beam model (HEB model) of the shield tunnel segment structure based on a systematical analysis of the stress state of the cross section of segment joints.

In previous studies, it can be seen that studies on the structural mechanical response under the influence of tunnel lining void are mainly focused on mountainous tunnels, while there are just a few studies on the cavity behind the shield tunnel lining and the research instrument is relatively single. Therefore, it is an urgent problem to clarify the mechanism of damage caused by lining cavities in subway shield tunnels. This paper takes shield tunnel as the research object and considers the effects of the angle, depth, and the number of voids on the shield tunnel lining structure, respectively, to more systematically and comprehensively reveal the interaction mechanism between the void lining and the surrounding rock based on the Nanchang Metro Shield Tunnel in Jiangxi Province in China. Meanwhile, indoor model tests and numerical simulations are used for analysis, and the model test results are compared with numerical simulations by similar ratio conversion to verify each other.

\section{Model Test Design}

2.1. Model Test Instruments and Equipment. The instruments and equipment required in the test are model box, water pressure gauge, Earth pressure box, percentage gauge, strain gauges, and dynamic and static strain gauges, etc., as shown in Figure 1. The overall size of the model box is $3000 \mathrm{~mm} \times 600 \mathrm{~mm} \times 2000 \mathrm{~mm} \quad$ (length $\times$ width $\times$ height, the frame is surrounded by $12 \mathrm{~mm}$ thick transparent tempered glass, and the bottom plate is made of $8 \mathrm{~mm}$ thick steel plate to bear the overlying load. The front and rear panels are symmetrically arranged with two diagonal braces. Considering the problems of tunnel segment placement, displacement meter installation, and pipeline arrangement in the test process, the front and rear two pieces of tempered glass are perforated with a hole diameter of $700 \mathrm{~mm}$.

2.2. Test Materials. This paper relies on the Nanchang Metro Shield Tunnel, which has an outer diameter of $6200 \mathrm{~mm}$, an inner diameter of $5600 \mathrm{~mm}$, and a ring width of $1200 \mathrm{~mm}$, and mainly traverses water-rich sand layers and clayey rocks layers, which have low cohesion, so the soil was simulated by Ganjiang river sand with $5 \mathrm{~mm}$ sieve. The basic physical and mechanical parameters were determined by direct shear, sieve, specific gravity of soil particles, and water content tests [21] as shown in Table 1. In the direct shear test, four specimens are taken for each group of tests and tested under four different vertical pressures to determine the shear stress of the soil under different vertical pressures. The vertical pressure was taken as $100 \mathrm{kPa}, 200 \mathrm{kPa}, 300 \mathrm{kPa}$, and 


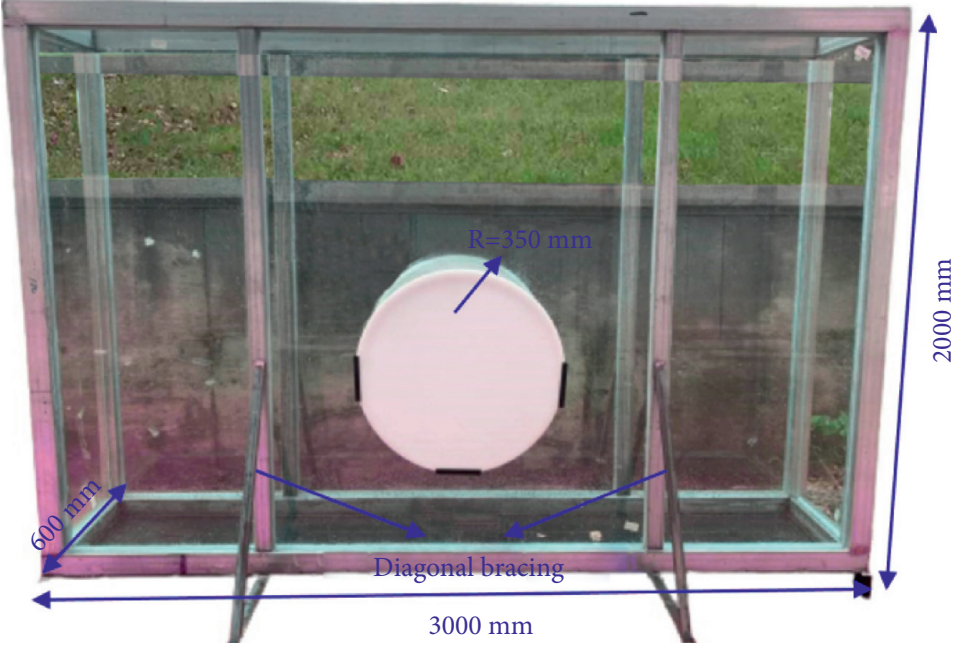

(a)

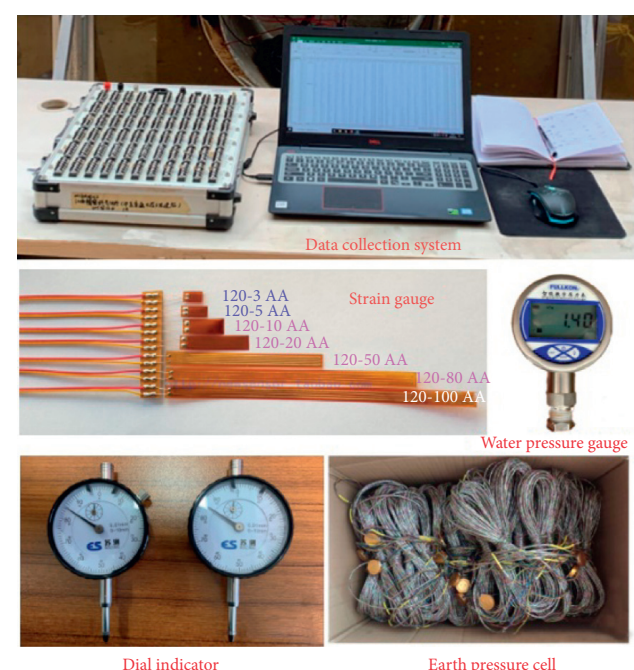

(b)

Figure 1: Model test equipment. (a) Test modal box. (b) Test monitoring instruments and equipment.

TAble 1: Physical and mechanical parameters of the soil.

\begin{tabular}{lccccc}
\hline Parameter & Water content $(\%)$ & Internal friction angle $\left({ }^{\circ}\right)$ & Specific gravity of soil particles & Pore ratio & Gravity $\left(\mathrm{kN} / \mathrm{m}^{3}\right)$ \\
\hline Value & 4.38 & 31.2 & 2.178 & 0.583 & 18.6 \\
\hline
\end{tabular}

$400 \mathrm{kPa}$, which was applied at once or in a graded manner according to the softness of the soil to prevent the specimen from extrusion. Then, representative samples were taken from the air-dried soil samples by the quarter diagonal method, and the particle sieving test was performed to determine the particle gradation of the sampled soil. At the same time, the specific gravity of the test soil is determined by the specific gravity bottle method, and $50 \mathrm{~g} \sim 100 \mathrm{~g}$ of the test soil is taken and put into the weighing box to weigh the wet soil mass and then put into the $105^{\circ} \mathrm{C} \sim 110^{\circ} \mathrm{C}$ oven to dry it to a constant amount, thus measuring the water content of the test soil.

The geometric similarity ratio between the prototype and the model was determined to be $10\left(C_{l}=10\right)$, and the model tunnel was simulated using 4 rings with an outer diameter of $620 \mathrm{~mm}$ and a ring width of $120 \mathrm{~mm}$ steel rings, without considering the annular joints of the segment in the cross section, and with 4 pairs of bolts between the rings (Figure 2(a)). The radial bending modulus of elasticity of the rings was determined to be $174.52 \mathrm{GPa}$ (Figure 2(b)) by means of a counterpressure test [22]. The lining structure is mainly subjected to bending, and its safety can be discerned by its bending force and deformation, so the model is simulated with the prototype equivalent bending stiffness EI, and the final control of its wall thickness is $8 \mathrm{~mm}$.

A prefilled water bladder was placed at the top of the vault to simulate the formation of the cavity by releasing the pressure step by step. In order to effectively obtain the deformation and force law of the segment structure, the size of the water bladder was taken as $250 \mathrm{~mm} \times 250 \mathrm{~mm} \times 150 \mathrm{~mm}$ (length $\times$ width $\times$ height), corresponding to the prototype angle of $0^{\circ}$ and depth of $1.5 \mathrm{~m}$.
The water filling port was set on the surface of the water bladder, and the bottom of the front and back was connected to the water stop valve and pressure gauge, respectively, through the hose, and the pressure can be accurately controlled by the pressure gauge reading during the test, as shown in Figure 3.

2.3. Test Scheme Design. There are three working conditions in this test, which are no cavity, cavity behind the vault, and the cavity behind the arch waist. The initial state of the test is when the water bladder is filled with water, i.e., the case of no cavity in the segment. When the water bladder pressure is released to the pressure gauge reading of zero, it is the final state of the test, and the test data is collected after the force and deformation are stabilized.

The middle two rings of the segment are used as the measurement object, and the two sides of the rings are used as the restraint. The measured data is the internal force of the lining structure, as shown in Figure 4. The internal force of the structure is measured by pasting resistance strain gauges on the inner and outer surfaces of the liner, and a pair is arranged at $45^{\circ}$ intervals.

According to the measured data, the axial force and bending moment values of the segment structure can be calculated, and the calculation formula is as follows:

$$
\begin{gathered}
N=\frac{E\left(\varepsilon_{\text {inner }}+\varepsilon_{\text {outer }}\right) b h}{2}, \\
M=\frac{E\left(\varepsilon_{\text {inner }}-\varepsilon_{\text {outer }}\right) b h^{2}}{12},
\end{gathered}
$$




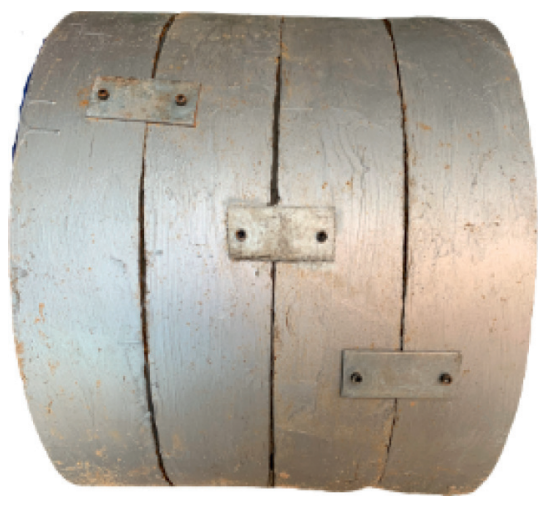

(a)

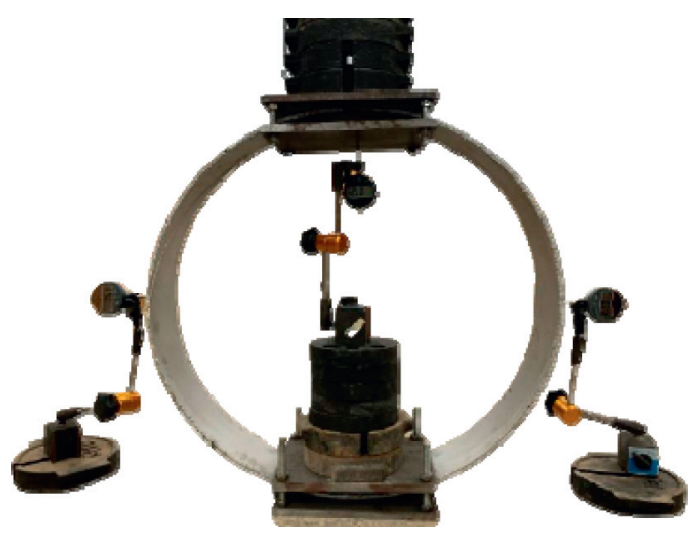

(b)

Figure 2: Shield tunnel model. (a) Segment structure. (b) Segment to pressure test.

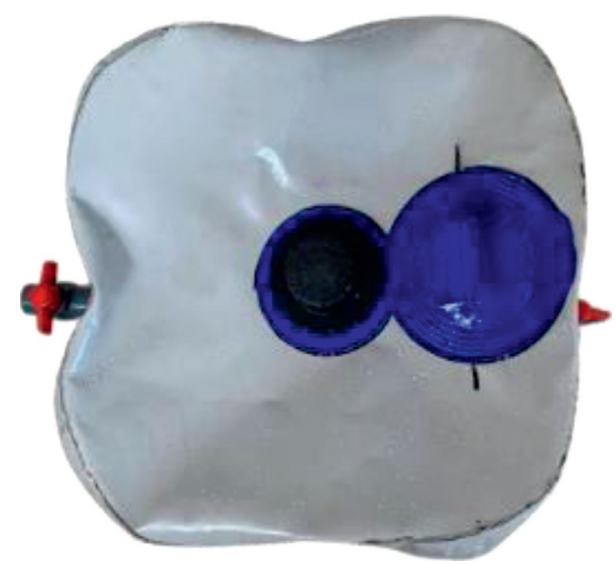

Figure 3: Model test water bladder.

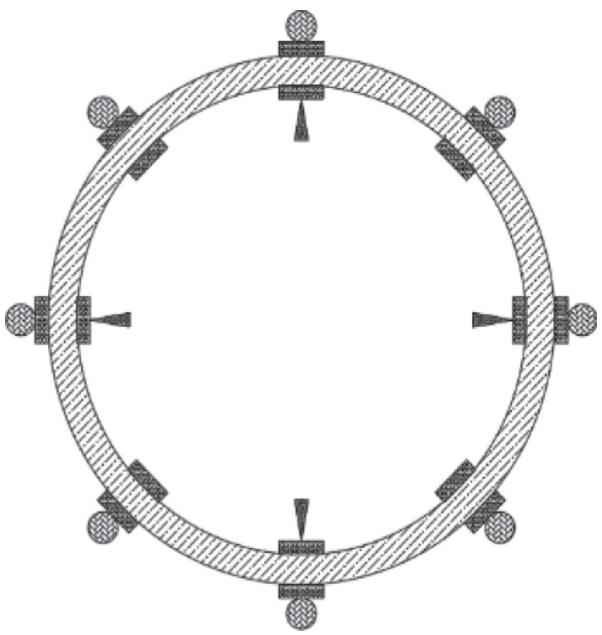

Strain gauge
Dial indicator
Earth pressure cell

Figure 4: Layout of monitoring points. where $E$ is the lining modulus of elasticity, and, respectively, $\varepsilon_{\text {inner }}$ and $\varepsilon_{\text {outer }}$ are the strain value of the inner and outer surface of the lining, $b$ is the section width, and $h$ is the thickness of the lining.

According to the strain value measured by the Earth pressure box, the contact pressure value behind the segment structure can be calculated, and the calculation formula is as follows:

$$
P=\mu \varepsilon \cdot K
$$

where $P$ is the pressure value, $\mu \varepsilon$ is the strain value, and $K$ is the sensitivity coefficient.

The specific test steps are as follows:

(1) Polish, paint, and assemble the model shield tunnel pipe pieces, then drill holes for each ring, and connect the pieces longitudinally with bolts.

(2) Mark the measured position with a $4 \mathrm{H}$ pencil, clean the measured position with industrial acetone solution, and paste the strain gauges.

(3) Apply medical petroleum jelly evenly on the inside of the tempered glass of the model test stand to reduce the frictional resistance between it and the test soil.

(4) The test soil is filled in layers by the "rainfall method," with the thickness of each layer being $200 \mathrm{~mm}$, and compacted by vibration with a vibrating compactor.

(5) When the soil is filled to a height of $300 \mathrm{~mm}$, the model shield tunnel is placed in the pedestal from the toughened glass opening, and the Earth pressure box is placed on the contact surface between the liner and the soil.

(6) When the soil is filled to the bottom of the test cavity, the water bladder is placed in the cavity and the hose at each end of the bladder is connected to the water stop valve and the pressure gauge, respectively.

(7) Connect the strain gauges and Earth pressure box wires to the strain gauge measurement channel, and open the DHDAS dynamic signal acquisition software for setting and collecting data. 
(8) According to the pressure gauge reading, open the water stop valve and discharge the water-filled water bladder in three stages, and then record the percentage gauge, strain gauge, and Earth pressure box data after it is stabilized.

\section{Numerical Simulation Analysis of Structural Response of Subway Shield Tunnel Lining under the Influence of Single Cavity}

Considering the high cost and time consuming of the test, in this paper, numerical simulation is carried out on the basis of experiments, which is in accordance with the measured methods in previous references [23-25]. Firstly, the finite element model was verified for correctness, then the beamspring model was introduced to consider the stiffness weakening at the shield tube joints, and its feasibility was demonstrated by comparing with the model test results. A two-dimensional plane model was established to analyze the effect of the angle and depth of the cavity on the shield tunnel.

\subsection{Verification of the Feasibility of the Numerical Simula-} tion of the Shield Tunnel under the Influence of a Cavity. A two-dimensional plane strain model was established using Midas/GTS finite element software for the numerical simulation of the shield tunnel without a cavity behind the tunnel, with the model size corresponding to the model test prototype size, which was taken as $30 \mathrm{~m} \times 20 \mathrm{~m}$ (length$\times$ height). The soil is simulated by plane strain elements and Mohr-Coulomb constitutive law is selected, the segment is simulated by beam elements, and elastic constitutive law is selected. The total number of elements is 3718 , the minimum size is $0.2 \mathrm{~m}$, and the maximum size is $0.6 \mathrm{~m}$, as shown in Figure 5. The physical and mechanical parameters of tunnel segment and stratum are corresponding to the prototype material of the model test through a similarity relationship.

Based on the cavity-free condition, the above model test reduction values are compared and analyzed with the numerical simulation calculated values, and the values of axial force, bending moment, and contact pressure with the surrounding strata are compared and verified, as shown in Figure 6.

From the figure, it can be seen that the overall distribution pattern of the model test reduction values and the numerical simulation calculated values are consistent, and the two are in good agreement. Due to the influence of the error in the test process, there is a difference in the values between the two, but it is small. Therefore, the numerical simulation can better restore the model test results, and it can be proved that the following extended analysis of the model test using numerical simulation is feasible.

In order to verify that the numerical simulation results can better reflect the actual engineering conditions, the model test values are restored according to similar relationships and compared with the numerical simulation values of the axial force and a bending moment of the segment under the cavity conditions behind the vault and arch waist.

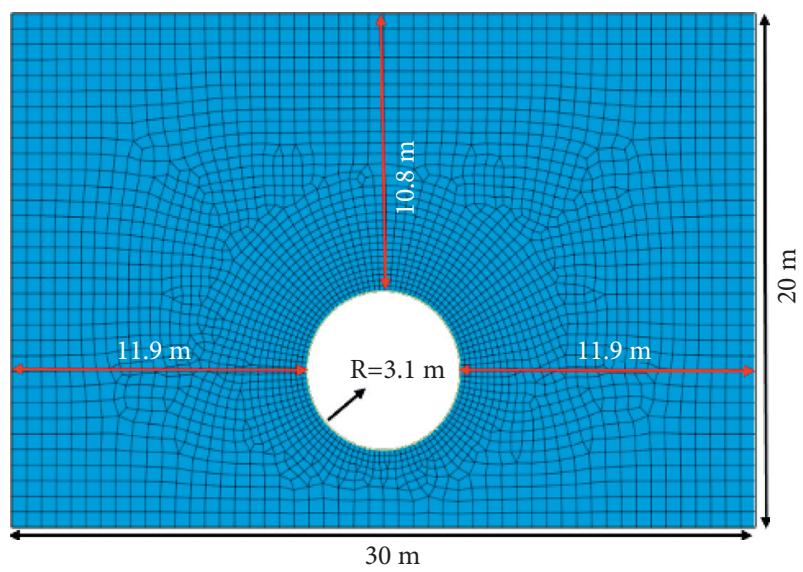

FIGURE 5: Numerical simulation of model test prototype.

For a typical shield underpass tunnel in Nanchang, a two-dimensional plane strain model is established. The stratigraphic-structural method is used to simulate the interaction between the segment and the strata, and the beamspring model simulates the stiffness weakening effect at the segment joints, and the spring parameters are shown in Table 2.

The model size is $36 \mathrm{~m} \times 24 \mathrm{~m}$ (length $\times$ height), Mohr-Coulomb constitutive law is used for all soil, and beam elements are used for the segment, which is an elastic constitutive law with $6200 \mathrm{~mm}$ outer diameter and $5600 \mathrm{~mm}$ inner diameter. The segment and its surrounding soil layer are treated with grid encryption, and the bottom and side displacements of the model are constrained; the model is shown in Figure 7. The total number of elements is 9926 , with a maximum size of $0.5 \mathrm{~m}$ and a minimum size of $0.1 \mathrm{~m}$. The cavity is realized by "weakening elements". According to the geological survey report and hydrological data, the average underground water level is $-8 \mathrm{~m}$. Therefore, the soil layer above the water table is taken as the natural gravity in the numerical model, and the soil below the water table is taken as the saturated gravity. The physical and mechanical parameters of the segment and soil layer in the area of Nanchang metro are shown in Table 3.

From Figures 9 and 10, it can be seen that, due to the modeling calculation using the stratigraphic parameters of Nanchang metro, there are differences in the values of axial force and bending moment between the prototype model test and the numerical simulation, but they are basically the same in numerical magnitude. And the distribution laws of axial force and bending moment values of the segment under different cavity location conditions calculated by this method are in good agreement, which further verifies the correctness of the research method in this paper.

3.2. Calculation of Tunnel Lining Safety Coefficient. In order to better reflect the safety and reliability of the structural elements, the safety coefficient of the tunnel lining structure is calculated according to the code [26-28], and the calculation formula is as follows: 


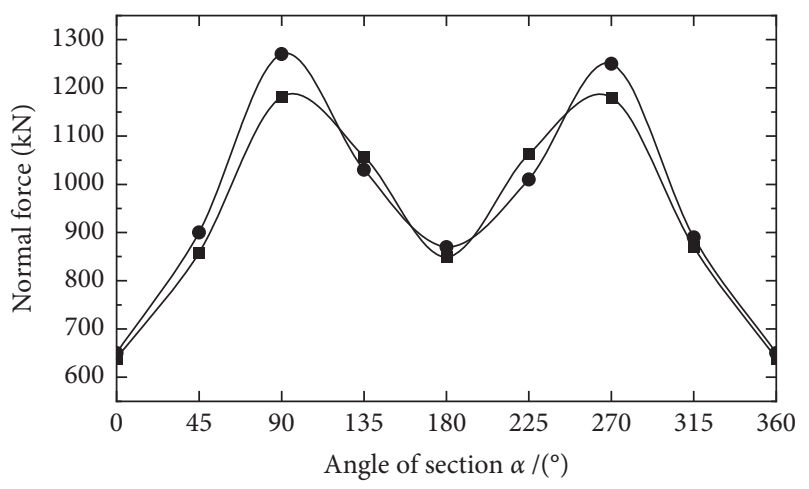

$\rightarrow-$ Calculated value of numerical simulation $\rightarrow$ Reduction value of model test

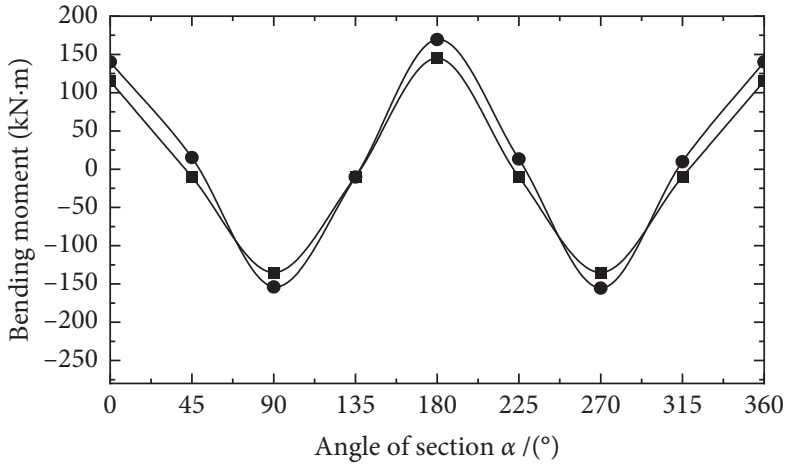

Calculated value of numerical simulation

Reduction value of model test

(b)

(a)

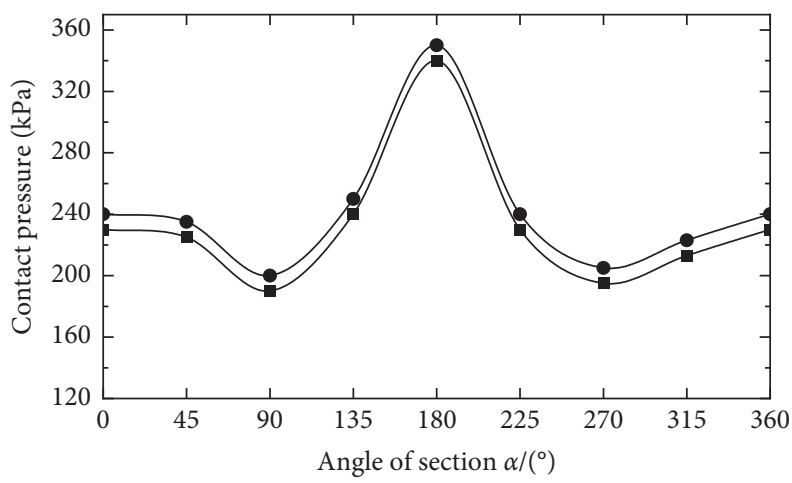

Calculated value of numerical simulation

Reduction value of model test

(c)

Figure 6: Comparison of numerical simulation values and model test reduction values. (a) Axial force value. (b) Bending moment value. (c) Contact pressure value.

TABLE 2: Beam-spring method mechanical model parameters.

\begin{tabular}{lcr}
\hline Normal stiffness $k_{n}\left(\mathrm{kN} \cdot \mathrm{m}^{-1}\right)$ & Tangential stiffness $k_{r}\left(\mathrm{kN} \cdot \mathrm{m}^{-1}\right)$ & ${\text { Rotational stiffness } k_{\theta}\left(\mathrm{kN} \cdot \mathrm{m} \cdot \mathrm{rad}{ }^{-1}\right)}^{7.2 \times 10^{7}}$ \\
\hline
\end{tabular}

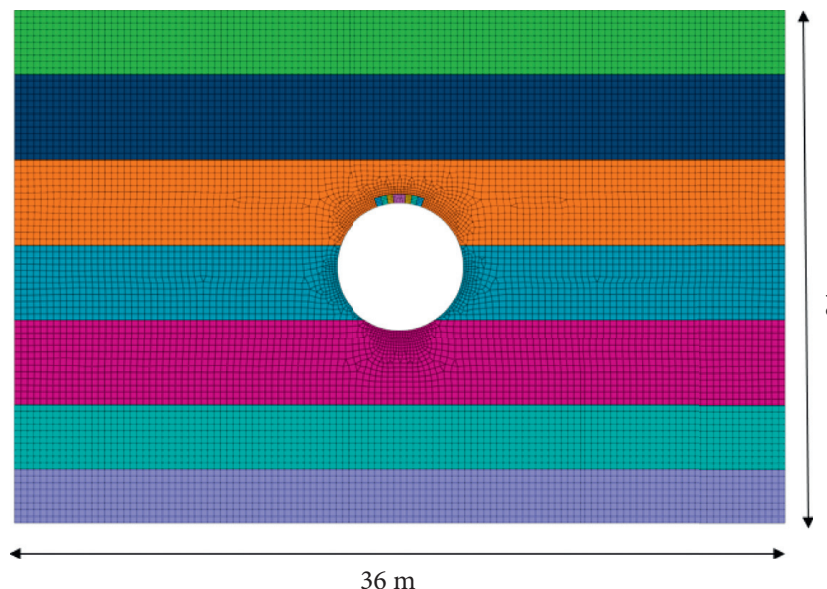

(a)

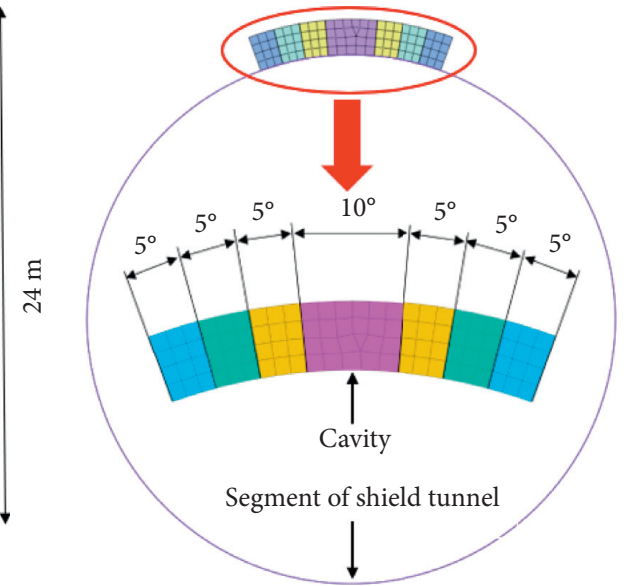

(b)

Figure 7: Finite element model diagram. (a) Overall view. (b) segment structure view. 
TABLE 3: Physical and mechanical parameters of soil layers.

\begin{tabular}{|c|c|c|c|c|c|c|c|}
\hline Soil type & $\begin{array}{c}\text { Natural } \\
\text { gravity } \\
\gamma / \mathrm{kN} \cdot \mathrm{m}^{-3}\end{array}$ & $\begin{array}{c}\text { Saturated } \\
\text { gravity } \\
\gamma_{\text {sat }} / \mathrm{kN} \cdot \mathrm{m}^{-3}\end{array}$ & $\begin{array}{l}\text { Friction } \\
\text { angle } \varphi /^{\circ}\end{array}$ & $\begin{array}{l}\text { Cohesion } \\
\text { force } c / \mathrm{kPa}\end{array}$ & $\begin{array}{c}\text { Poisson's } \\
\text { ratio/ } \mu\end{array}$ & $\begin{array}{c}\text { Elastic modulus } \\
E / \mathrm{MPa}\end{array}$ & $\begin{array}{c}\text { Layer } \\
\text { thickness } / \mathrm{m}\end{array}$ \\
\hline Miscellaneous fill & 18.5 & 19.1 & 13 & 11 & 0.30 & 14 & 3.0 \\
\hline Silty clay & 19.5 & 20.4 & 12 & 28 & 0.36 & 18 & 4.0 \\
\hline Medium sand & 20.5 & 21.8 & 30 & 0 & 0.30 & 30 & 4.0 \\
\hline Coarse sand & 20.5 & 21.9 & 33 & 0 & 0.30 & 32 & 3.5 \\
\hline Gravelly sand & 21.3 & 22.1 & 37 & 0 & 0.30 & 34 & 4.0 \\
\hline Strongly weathered muddy siltstone & 22.4 & 22.5 & 25 & 40 & 0.32 & 80 & 3.0 \\
\hline Moderately weathered muddy siltstone & 24.1 & 24.5 & 32 & 350 & 0.26 & 790 & 2.5 \\
\hline Tunnel segment (C50) & - & 26.5 & - & - & 0.2 & $3.1 \times 10^{4}$ & - \\
\hline
\end{tabular}

Note. The horizontal coordinates of the graphs in the article correspond to the location of the tunnel liner section as shown in Figure 8, and the graphs below with the angle as the horizontal coordinate are all based on this standard.

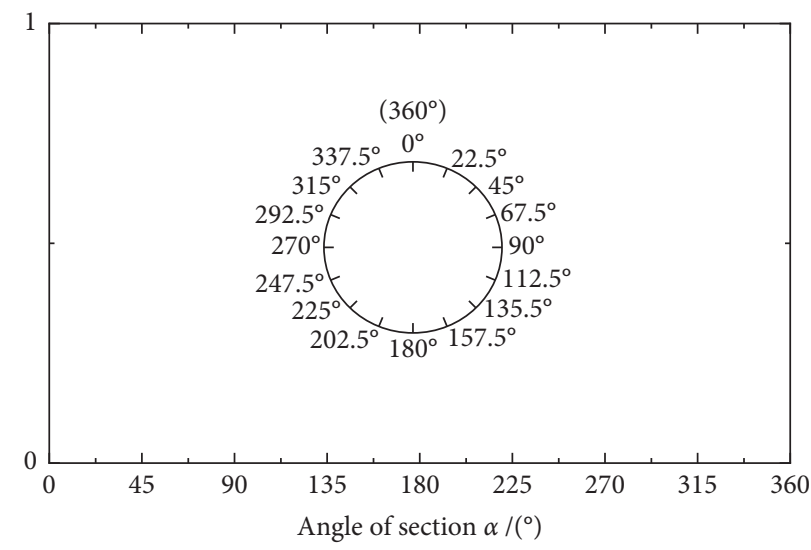

FIGURE 8: Horizontal coordinates corresponding to the location of the tunnel segment.

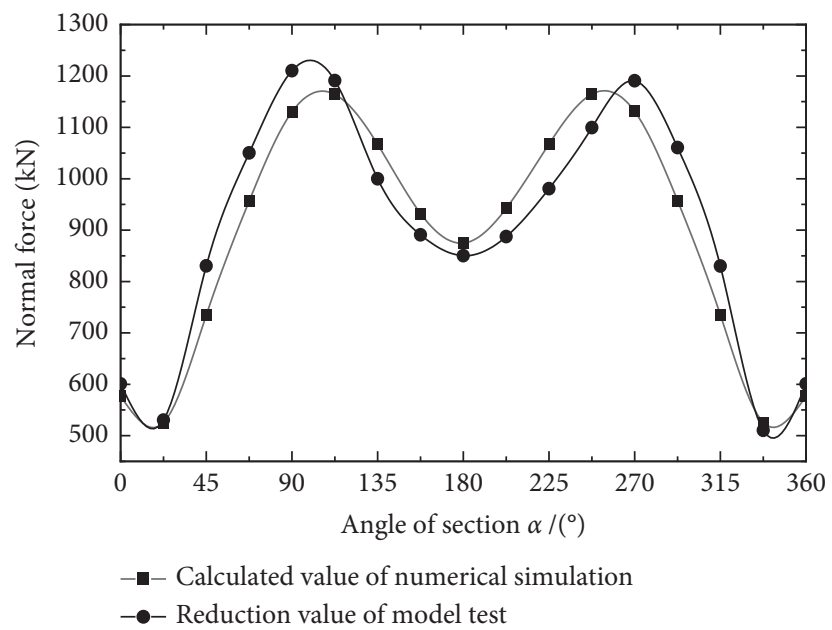

Figure 9: Comparison of axial force values of the cavity behind the vault (unit: $\mathrm{kN}$ ).

$$
k=\frac{N_{\text {limit value }}}{N} \geq k_{\text {standard value }}
$$

When controlled by the compressive strength of the tunnel, i.e., $e=(M / N) \ll 0.2 h$, then

$$
N_{\text {limit value }}=\varphi \alpha R_{a} h b \text {, }
$$

where $\varphi$ is the longitudinal coefficient of the member; the tunnel lining structure can be taken as $1 . R_{a}$ is the ultimate compressive strength of concrete. $\alpha$ is the coefficient of eccentric influence of axial forces; $b$ is the width of the tunnel cross section, taken as $1 ; h$ is the thickness of the tunnel section; and $e$ is the axial force eccentricity distance. 


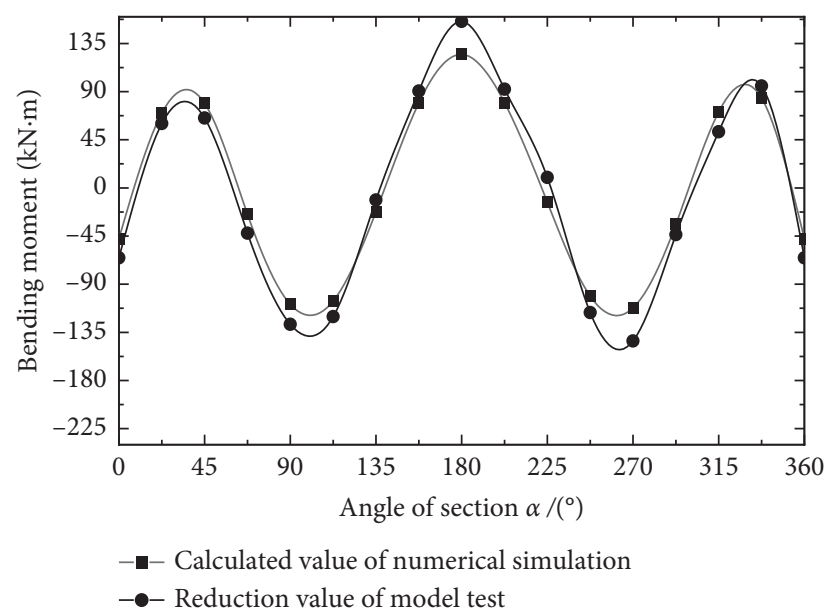

FIgure 10: Comparison of bending moment values of the cavity behind the vault (unit: $\mathrm{kN} \cdot \mathrm{m}$ ).

When controlled by the tensile strength of the tunnel, i.e., $e=(M / N) \gg 0.2 h$, then

$$
N_{\text {limit value }}=\varphi \frac{1.75 R_{t} h b}{(6 e / h)-1}
$$

where $R_{i}$ is the tensile ultimate strength of concrete.

\subsection{Numerical Simulation Analysis of Different Angle Cavities} behind the Segment. Based on the above numerical model, the calculation conditions shown in Table 4 are set for different angles of cavities behind the vault.

3.3.1. Axial Force Distribution. From Figure 11, affected by the cavity behind the vault, with the increase of the cavity angle, the range of the affected section of the segment increases gradually, the value of the axial force of the vault gradually decreases, and the value of the axial force of the vault under the gradual growth of the cavity angle reduces by $25.90 \mathrm{kN}, 38.93 \mathrm{kN}$, and $53.53 \mathrm{kN}$, respectively, compared with $10^{\circ}$. The maximum and minimum values of the axial force reduce, and the difference of the maximum value of the axial force of the segment gradually increases. The difference between the maximum and minimum values of axial force of lining at $10^{\circ}, 20^{\circ}, 30^{\circ}$, and $40^{\circ}$ cavity is $548.03 \mathrm{kN}, 569.88 \mathrm{kN}$, $602.75 \mathrm{kN}$, and $648.20 \mathrm{kN}$, respectively. And the larger the cavity angle is, the more uneven the axial force distribution of the segment is.

3.3.2. Bending Moment Distribution. From Figure 12, it can be seen that the cavity behind the vault causes the bending moment value at the vault of the segment to be reduced, and the bending moment is mainly borne by the adjacent section, which is consistent with the bending moment distribution law of the segment in the cavity behind the vault condition of the model test. Meanwhile, with the increase of the cavity angle, the affected range of the vault bending moment increases, and the decrease of the vault bending moment value is larger, and the change of the lining vault bending moment value under the gradual increase of the cavity angle is
TABle 4: Numerical simulation conditions of different angle cavities.

\begin{tabular}{lccc}
\hline Working condition & Cavity angle $\left({ }^{\circ}\right)$ & $\begin{array}{c}\text { Cavity } \\
\text { depth }(\mathrm{m})\end{array}$ & $\begin{array}{c}\text { Position of } \\
\text { cavity }\end{array}$ \\
\hline 1 & 10 & 0.4 & \\
2 & 20 & 0.4 & Vault \\
3 & 30 & 0.4 & \\
4 & 40 & 0.4 & \\
\hline
\end{tabular}

$42.90 \mathrm{kN} \mathrm{m}, 44.15 \mathrm{kN} \mathrm{m}$, and $40.86 \mathrm{kN} \mathrm{m}$, respectively. And the vault moment value and the cavity angle value are approximately linear. When $30^{\circ}$ and $40^{\circ}$ cavities appear behind the vault, the bending moment at the vault is reversed, and the outer side of the vault is changed from compressed to tensioned state, and the bending moment values of both sides of the vault increase and increase significantly.

3.3.3. Safety Coefficient. From Figure 13, the safety coefficient of the shield tunnel segment is distributed in a "butterfly shape" when there is no cavity, with the smallest safety coefficients at the vault and bottom of the arch, with values of 2.45 and 2.92, respectively, and the second largest safety coefficients at the waist of the arch on both sides, with values of 5.13 and 5.19, with larger safety coefficients at $45^{\circ}$, $135^{\circ}, 225^{\circ}$, and $315^{\circ}$ section positions, with values of 14.59 , $12.27,11.73$, and $14.3,5$ respectively. The safety coefficients are larger.

When there is a cavity behind the tunnel vault, the data obtained by the formula in Section 3.2 of this paper shows that the safety factor at the vault of the tube piece increases compared with that without the cavity because the unloading effect of the arch reduces the load on the vault. And the safety coefficients at $10^{\circ}, 20^{\circ}, 30^{\circ}$, and $40^{\circ}$ cavities behind the vault are $7.89,14.48,20.05$, and 13.42 , respectively, which indicates that the safety coefficient decreases when the angle reaches a certain value. The safety coefficients of the segment at $22.5^{\circ}, 45^{\circ}, 315^{\circ}, 337.5^{\circ}$, and other crosssections significantly reduce, and the safety coefficients of corresponding cross-sections reduce by $3.64,3.61,3.38$, and 


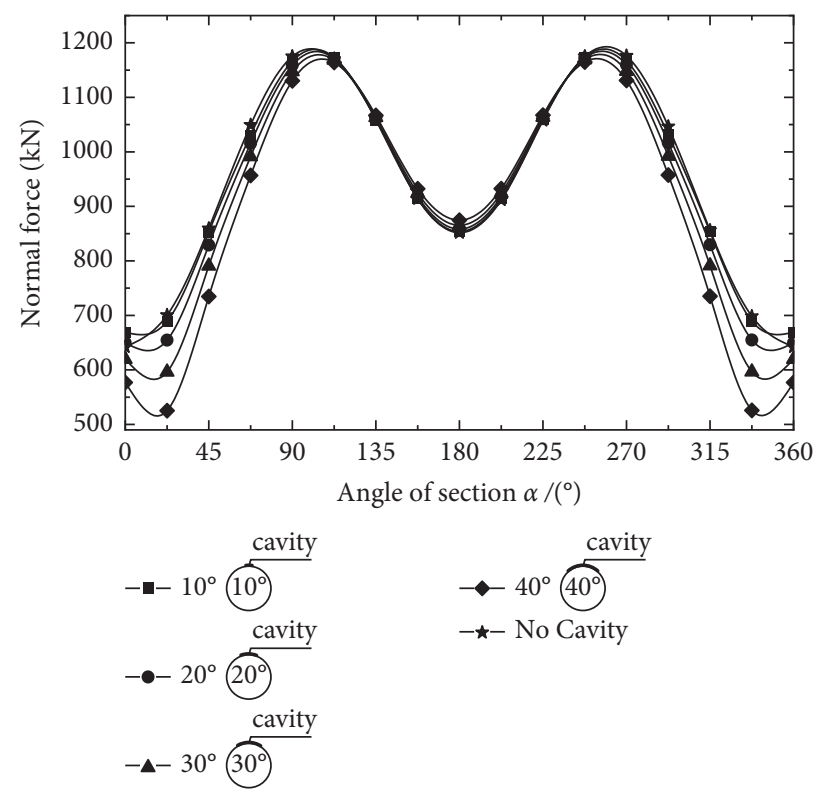

Figure 11: Axial force distribution of the segment at different angles of the cavity behind the vault (unit: $\mathrm{kN}$ ).

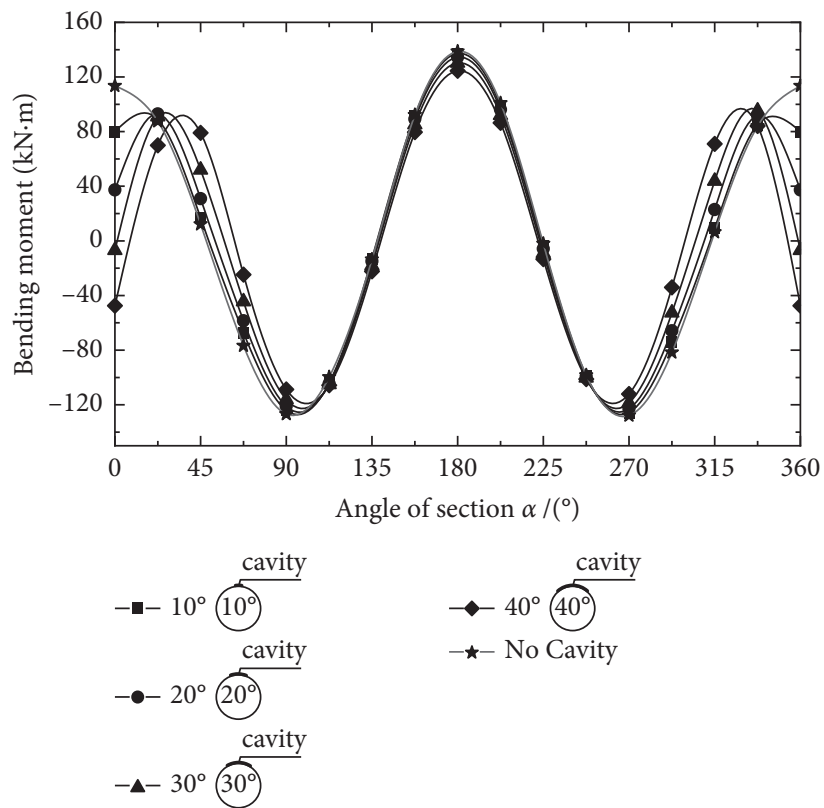

FIgURE 12: Distribution of bending moment of the segment at different angles of the cavity behind the vault (unit: $\mathrm{kN} \cdot \mathrm{m}$ ).

3.27 , respectively, when there is no cavity and $10^{\circ}, 20^{\circ}, 30^{\circ}$, and $40^{\circ}$ cavity conditions behind the vault.

\subsection{Numerical Simulation Analysis of Different Depth Cavities} behind the Segment. Modeling analysis is carried out for different depth cavities behind the lined arch waist, and the four cavity depth values are $0.2 \mathrm{~m}, 0.4 \mathrm{~m}, 0.6 \mathrm{~m}$, and $0.8 \mathrm{~m}$, respectively, and the calculated working conditions are shown in Table 5 . The model size is $36 \mathrm{~m} \times 24 \mathrm{~m}$ (length$\times$ height). The total number of elements is 13120 , the minimum dimension is $0.1 \mathrm{~m}$, and the maximum dimension is $0.3 \mathrm{~m}$, as shown in Figure 14, in which the model soil, segment, and segment joint are set in the same way as in Section 3.1, and the parameters of segment joint, segment, and soil layer are shown in Tables 2 and 3.

3.4.1. Axial Force Distribution. As shown in Figure 15, with the increase of the cavity depth, the axial force value at the left arch waist $\left(270^{\circ}\right.$ section) of the segment gradually increases, and the axial force value at the left arch waist $\left(270^{\circ}\right.$ section) of the segment increases by $114.21 \mathrm{kN}, 51.95 \mathrm{kN}$, and $30.45 \mathrm{kN}$, respectively, under the gradual increase of the 


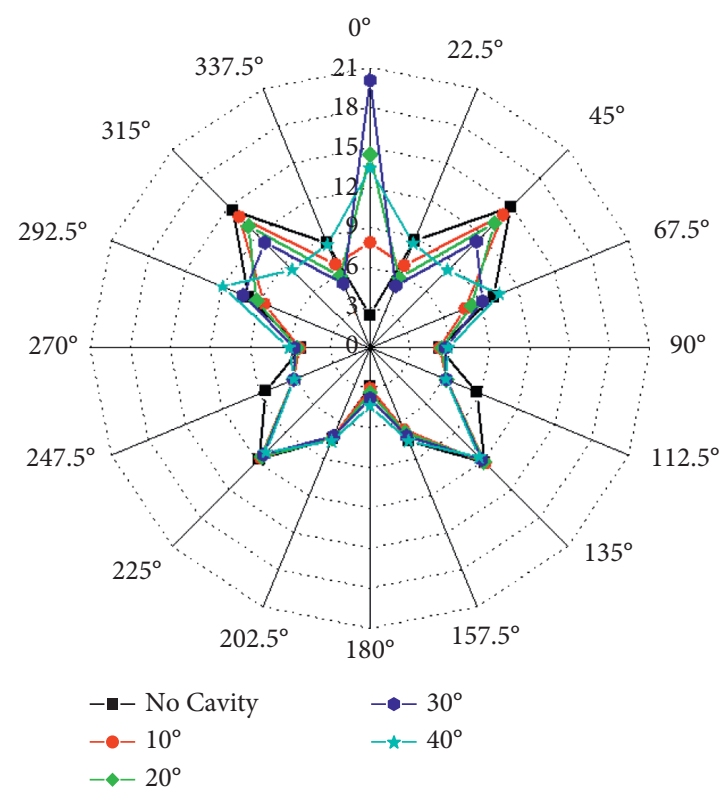

FIGURE 13: Safety coefficient of each section of the segment for different angle cavities behind the vault.

TABLE 5: Numerical simulation conditions of cavities at different depths.

\begin{tabular}{lccc}
\hline Working condition & Cavity angle $\left(^{\circ}\right)$ & Cavity depth $(\mathrm{m})$ & Cavity position \\
\hline 5 & 20 & 0.2 & Behind the arch waist \\
6 & 20 & 0.4 & 0.6 \\
7 & 20 & 0.8 & \\
8 & 20 & & \\
\hline
\end{tabular}

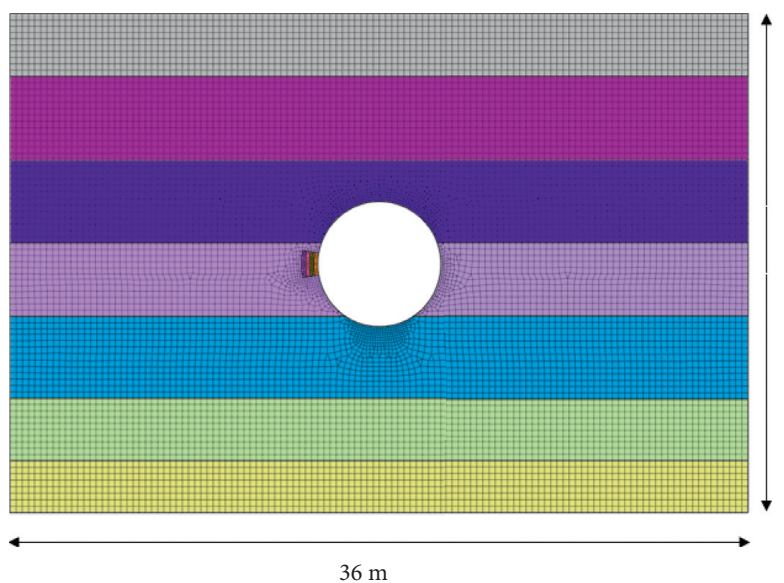

(a)

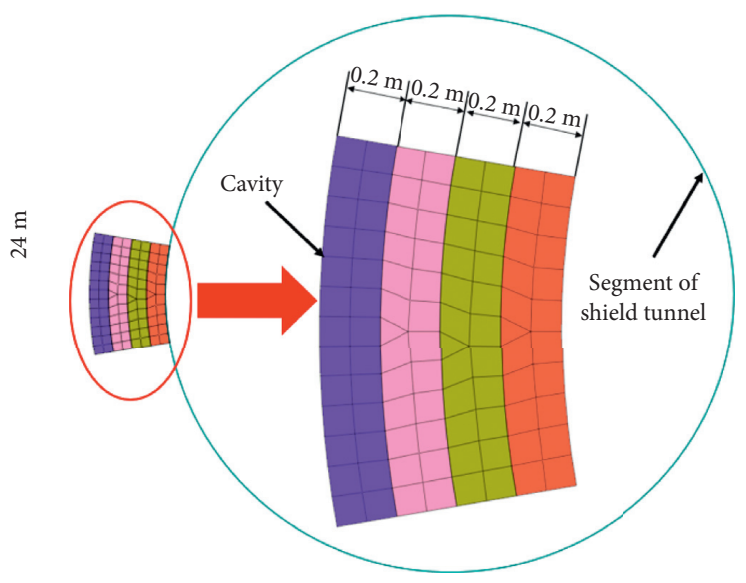

(b)

Figure 14: Numerical simulation model of the cavity at different depths. (a) Overall view. (b) Segment structure view.

cavity depth, which is the opposite of the cavity condition behind the vault. The maximum value of the axial force of the segment gradually increases, and the minimum value decreases slightly. The difference of the maximum value of the axial force of the segment gradually increases and the minimum value slightly decreases, while the difference of the maximum value of the axial force increases, and the difference of the maximum value of the axial force of the lining when the cavity behind the left vault is $0.2 \mathrm{~m}, 0.4 \mathrm{~m}, 0.6 \mathrm{~m}$, and $0.8 \mathrm{~m}$ deep is $565.38 \mathrm{kN}, 567.28 \mathrm{kN}, 581.87 \mathrm{kN}$, and $612.60 \mathrm{kN}$, respectively.

3.4.2. Distribution of Bending Moment. As can be seen from Figure 16, the presence of the cavity leads to the absence of strata at the corresponding location, the tunnel segment is 


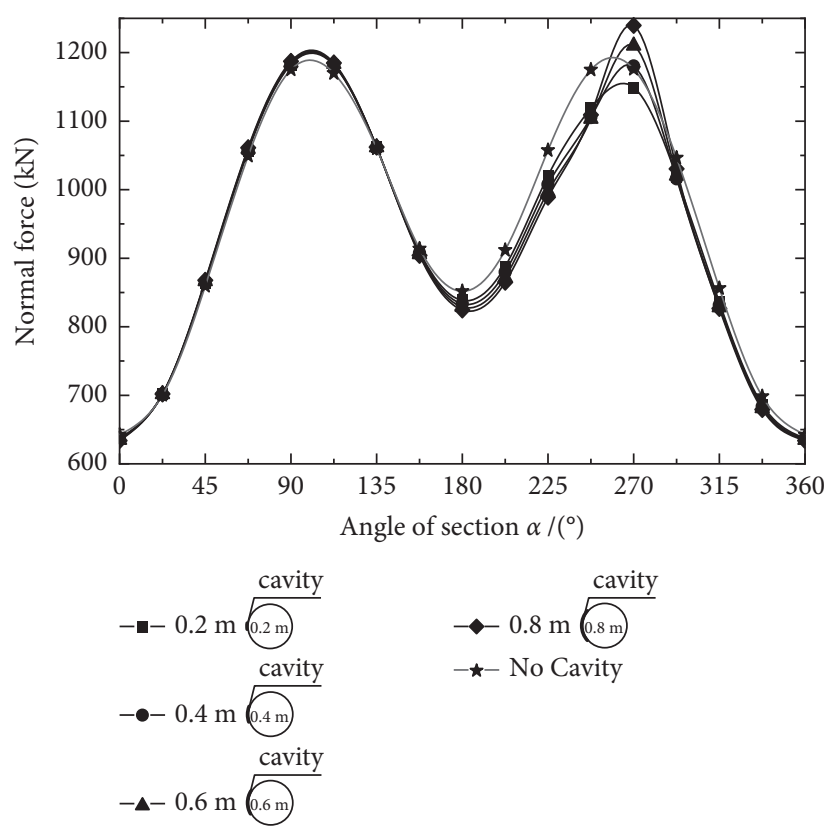

Figure 15: Distribution of axial force of the segment at different depths of the cavity behind the arch waist (unit: kN).

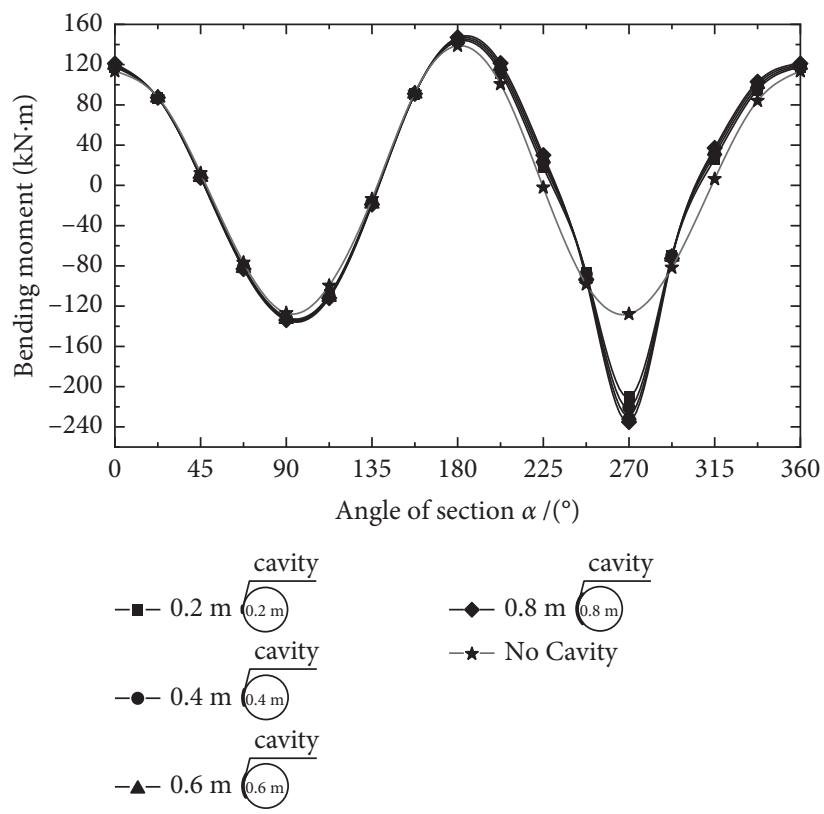

Figure 16: Distribution of bending moment of the segment at different depths of the cavity behind the arch waist (unit: $\mathrm{kN} \cdot \mathrm{m}$ ).

subject to bias pressure, not subject to stratigraphic reaction force, deformation displacement is not constrained, so the existence of the cavity leads to an increase in the value of bending moment at the left arch waist, the bending moment at the arch waist on both sides is asymmetrically distributed, and the overall bending moment distribution of the segment is tilted toward the location of the cavity. With the increase of the cavity depth, the bending moment at the left arch waist also increases further, and the increase of bending moment is $10.57 \mathrm{kN} \mathrm{m}, 8.05 \mathrm{kN} \mathrm{m}$, and $6.50 \mathrm{kN} \mathrm{m}$, respectively, under the gradual increase of the cavity depth, and the increased amplitude of bending moment decreases with the increase of the cavity depth, which indicates that the influence of the cavity depth on the segment is limited, and when the depth reaches a certain value, the influence of the continuous increase of depth on the segment is smaller.

3.4.3. Safety Coefficient. From Figure 17, it can be seen that the cavity behind the arch waist greatly reduces the safety of this section, when there is no cavity, the safety coefficient at the left arch waist is 5.18 , when there is a $0.2 \mathrm{~m}$ deep cavity 


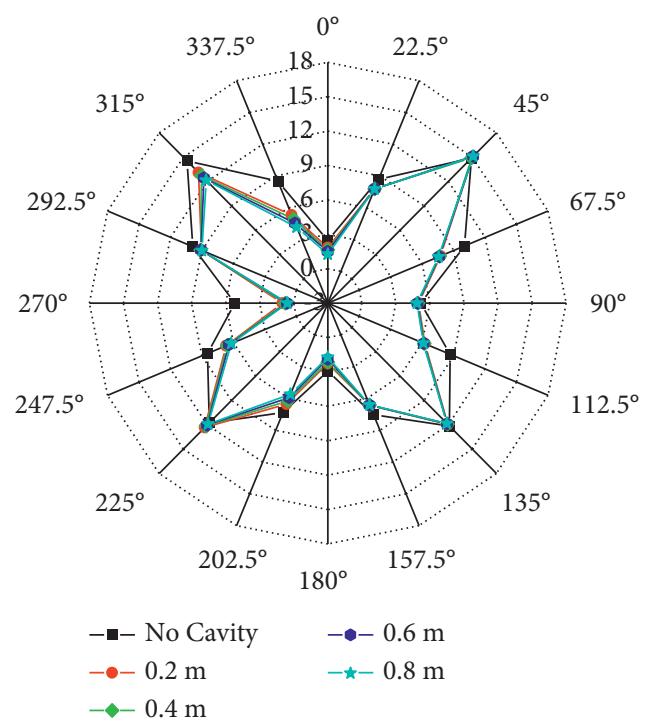

FIGURE 17: Coefficient of safety for each section of the segment at different depths of the cavity behind the arch waist.

behind the arch waist, and the safety coefficient is 0.98 , which reduces by $81.08 \%$, indicating that the cavity behind the arch waist has a greater impact on the safety of the tunnel segment. When there is no cavity, the safety coefficient at the top of the arch is 2.45 and the safety coefficient at the bottom of the arch is 2.92 . When there is a $0.2 \mathrm{~m}$ deep cavity behind the arch, the safety coefficient at the top of the arch is 1.85 , which reduces by $24.49 \%$, and the safety coefficient at the bottom of the arch is 2.26 , which reduces by $22.60 \%$, and the overall safety of the segment structure has a large degree of reduction. From Figure 18, it can be seen that the safety coefficient is further reduced by the gradual increase of the cavity depth, and the safety coefficients at the waist of the arch reduce by $0.23,017$, and 0.03 , respectively, the safety coefficients at the top of the arch reduce by $0.19,0.17$, and 0.21 respectively, and the safety coefficients at the bottom of the arch reduce by $0.12,0.26$, and 0.16 , respectively. The influence of depth on the safety of the segment is relatively limited.

The results of the analysis in Section 3 of this paper are more consistent with the conclusions of similar literature [29, 30]. Namely, the change of cavity size significantly changes the internal force distribution of the tunnel segment, and the increase of cavity size causes the axial force of the segment structure between cavities to decrease while the bending moment increases, which makes the damage of the tunnel segment more serious.

\section{Numerical Simulation Analysis of Structural Response of Subway Shield Tunnel Lining under the Influence of Multiple Cavities}

In actual projects, clusters of voids may appear behind shield tunnels, and the force condition of shield tunnel lining under the combination of multiple voids needs to be clarified. Therefore, in this section, based on the study of a single cavity, the effect of multicavity combination on shield tunnel is studied, and the working conditions under different combinations of the double cavity and triple cavity are modeled and analyzed, respectively. In the model, the cavity angle is $30^{\circ}$ and the depth is $0.4 \mathrm{~m}$. The longitudinal length of the cavity is not considered. The values of segment joints, lining, and soil parameters are shown in Tables 2 and 3, and the model size is $36 \mathrm{~m} \times 24 \mathrm{~m}$ (length $\times$ height).

4.1. Numerical Simulation Analysis of Double Cavity Combination Effect. Four sets of double cavity combination conditions were set up for finite element modeling calculation to analyze the axial force and bending moment distribution of shield tunnel lining under different cavity combinations, and the schematic diagram of each condition is shown in Figure 19.

4.1.1. Cavity behind the Vault and Arch Waist. As shown in Figure 20, when the cavity appears behind the vault and the arch waist of the segment at the same time, the axial force of the segment at the position of the corresponding section of the two cavities is larger than that at the sections on both sides, the transition of the axial force of the corresponding section of the cavity is not smooth, and the rate of change of the axial force is larger. The bending moment distribution law of the segment is similar to that of the single cavity working condition studied above, the cavity behind the vault causes the corresponding section bending moment to decrease, while the opposite increases at both sides of the vault. Due to the reduction of the load on the top of the vault, the safety coefficient at the top of the vault increases by 18.5 compared with that without the cavity, while the safety coefficients at other cross-sectional positions are reduced compared with those without the cavity, especially at the left side of the vault $\left(270^{\circ}\right.$ section) and $337.5^{\circ}$ section, where the safety coefficients reduce by 5.9 and 8.2, respectively, as shown in Figure 21. 


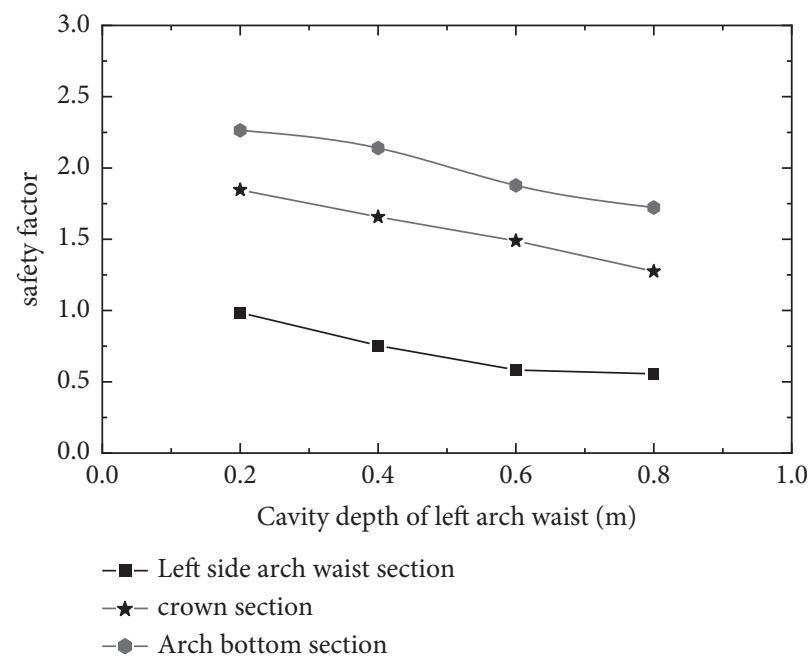

FIgURE 18: Variation law of safety coefficient of a typical section of the segment.

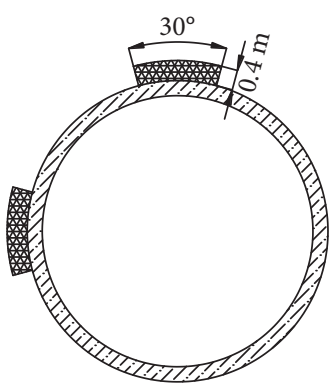

(a)

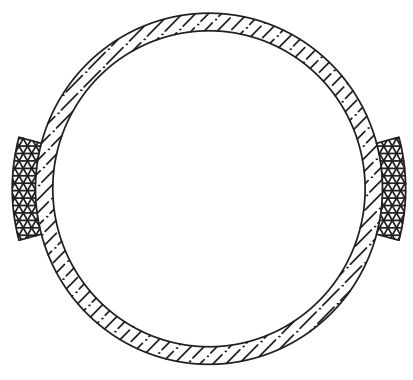

(b)

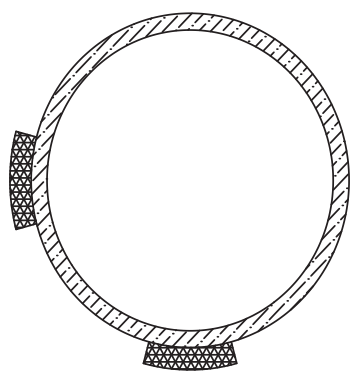

(c)

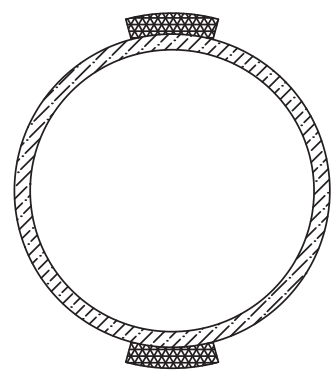

(d)

FIGURE 19: Combined working condition of double voids. (a) Vault and arch waist cavity. (b) Double-side arch waist cavity. (c) Arch waist and arch bottom cavity. (d) Arch top and arch bottom cavity.

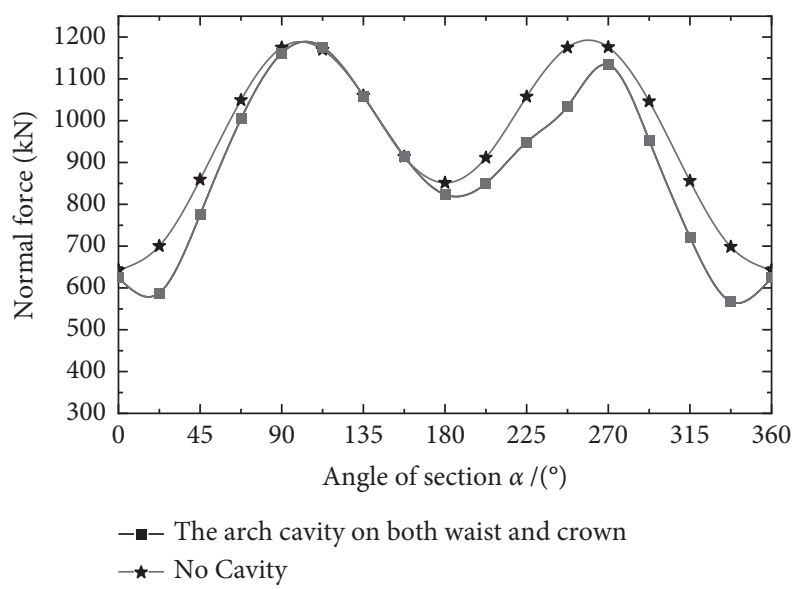

(a)

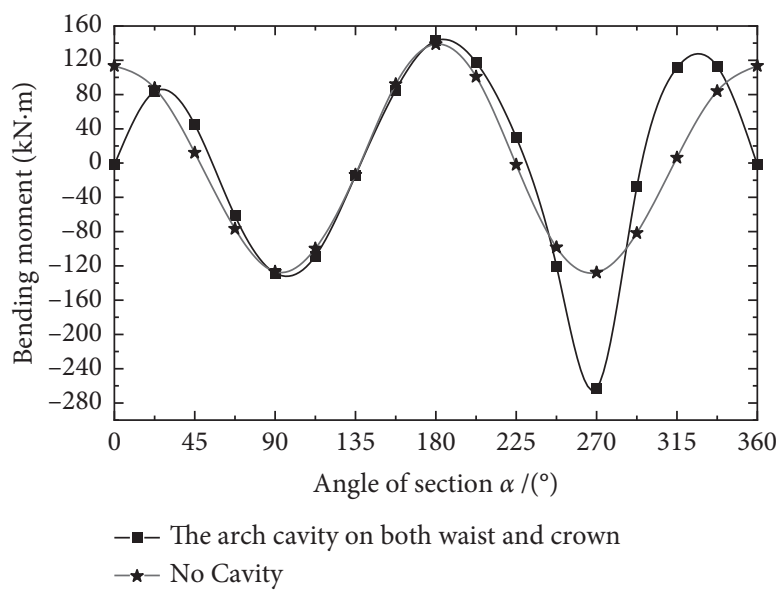

(b)

Figure 20: Internal force diagram of the cavity behind the vault and arch waist. (a) Segment axial force. (b) Segment bending moment.

4.1.2. Cavity behind the Arch Waist on Both Sides. As shown in Figure 22, the force law of the segment does not change when there is a cavity behind the arch waist on both sides compared with that without a cavity, and only the quantity value changes. The axial force and bending moment at both sides of the arch waist increase compared with those without a cavity, and the increase is larger. The maximum bending moment value of the segment under this working condition 


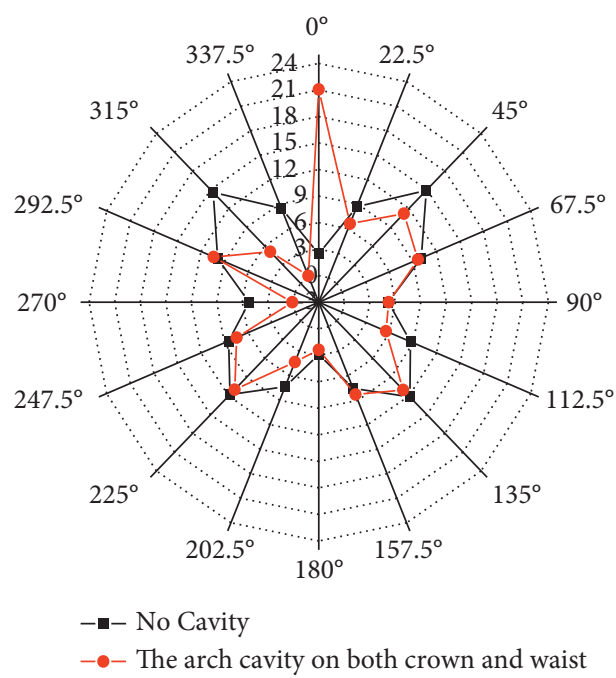

Figure 21: Safety coefficient of the segment cross section of the cavity behind the vault and arch waist.

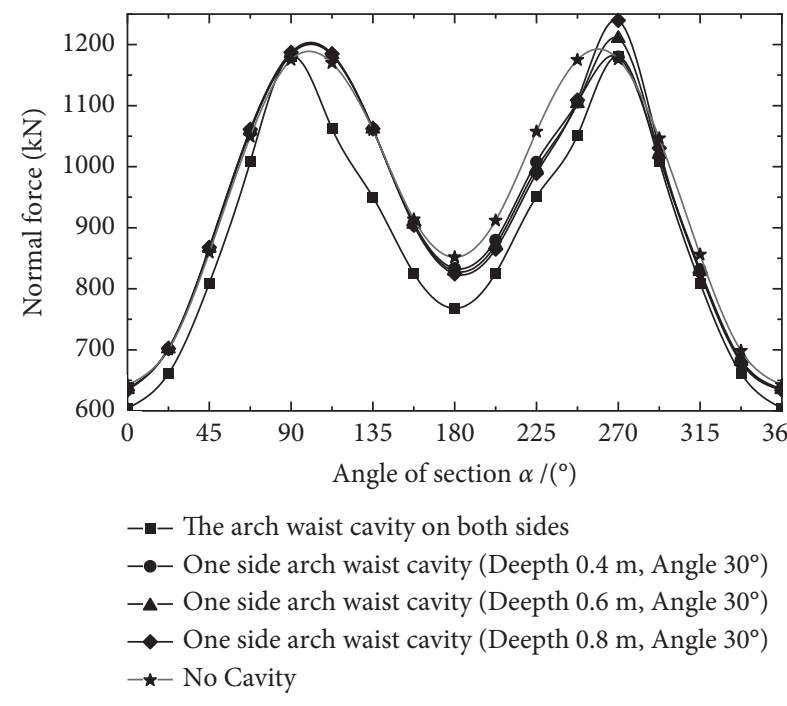

(a)

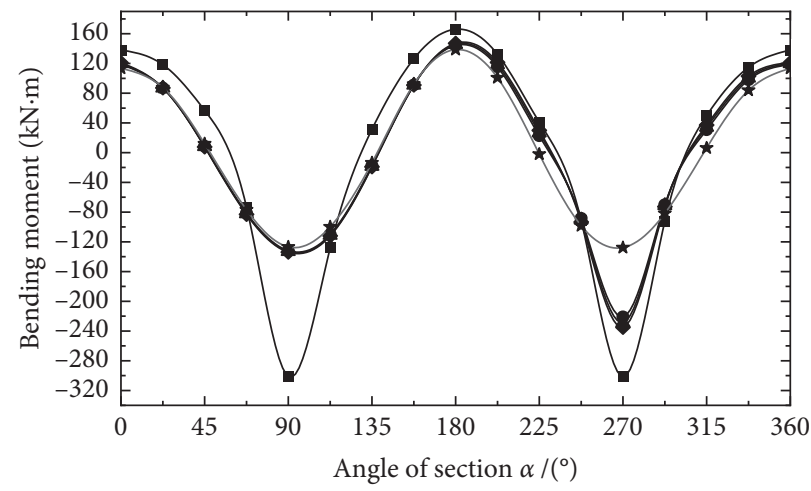

- - The arch waist cavity on both sides

- - One side arch waist cavity (Deepth $0.4 \mathrm{~m}$, Angle $30^{\circ}$ )

- $\mathbf{-}$ - One side arch waist cavity (Deepth $0.6 \mathrm{~m}$, Angle $30^{\circ}$ )

$\multimap-$ One side arch waist cavity (Deepth $0.8 \mathrm{~m}$, Angle $30^{\circ}$ )

$-\star-$ No Cavity

FIGURE 22: Internal force diagram of the cavity behind the arch waist on both sides. (a) Segment axial force. (b) Segment bending moment.

increases by $42.53 \%$ compared with the working condition of $20^{\circ}$ angle behind the arch waist and $0.4 \mathrm{~m}$ deep cavity, increases by $37.55 \%$ compared with the working condition of $20^{\circ}$ angle behind the arch waist and $0.6 \mathrm{~m}$ deep cavity, and increases by $34.04 \%$ compared with the working condition of $20^{\circ}$ angle behind the arch waist and $0.8 \mathrm{~m}$ deep cavity. The safety coefficient of the whole circumference section of the segment is reduced, among which the greatest reduction is at both sides of the arch waist and reduces to 0.1 magnitudes, and the structural safety performance of the segment at the arch waist reduces more, as shown in Figure 23.

4.1.3. Cavities behind Arch Waist and Arch Bottom. As shown in Figure 24, when there is a cavity behind the arch waist and arch bottom, the force law of the segment is more similar to that of the cavity behind the vault and arch waist.
Compared with the condition without a cavity, the transition of axial force value at the corresponding section of the cavity is not smooth, and the bending moment value at the bottom of the arch of the segment is reduced, but the reduction is slightly smaller than that at the cavity behind the vault and arch waist; the bending moment value at the arch waist increases significantly. The safety coefficient at the bottom of the arch of the segment increases by 13.2, and the safety coefficients at other cross-sectional positions reduce among which the reduction was most obvious at the left side of the arch waist and at both sides of the arch bottom, as shown in Figure 25.

4.1.4. Cavities behind the Vault and the Bottom of the Vault. As shown in Figure 26, when the cavities appear behind the vault and arch bottom of the segment at the same time, the 


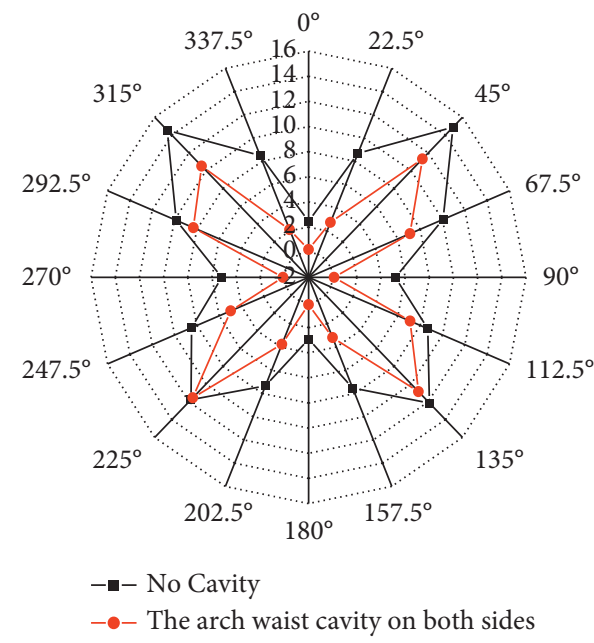

FIGURE 23: Safety coefficient of the segment cross section of the cavity behind the arch waist on both sides.

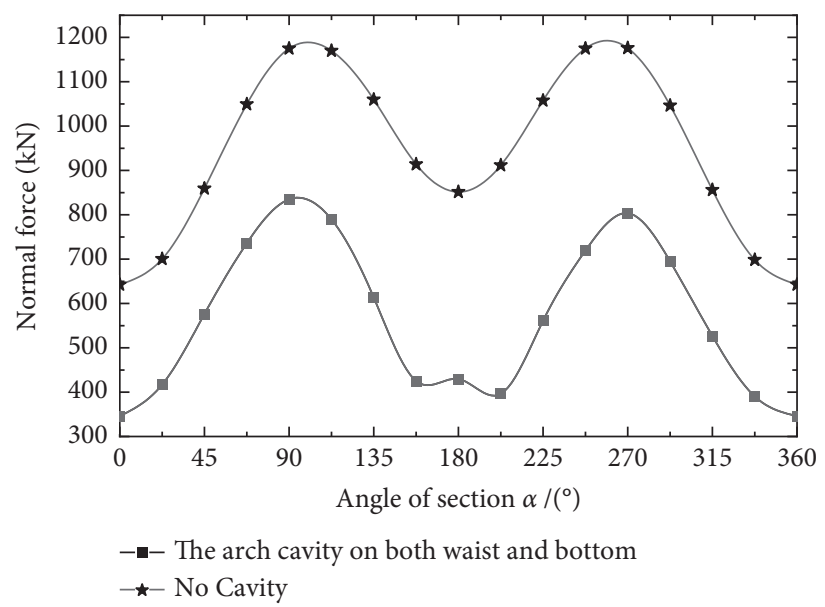

(a)

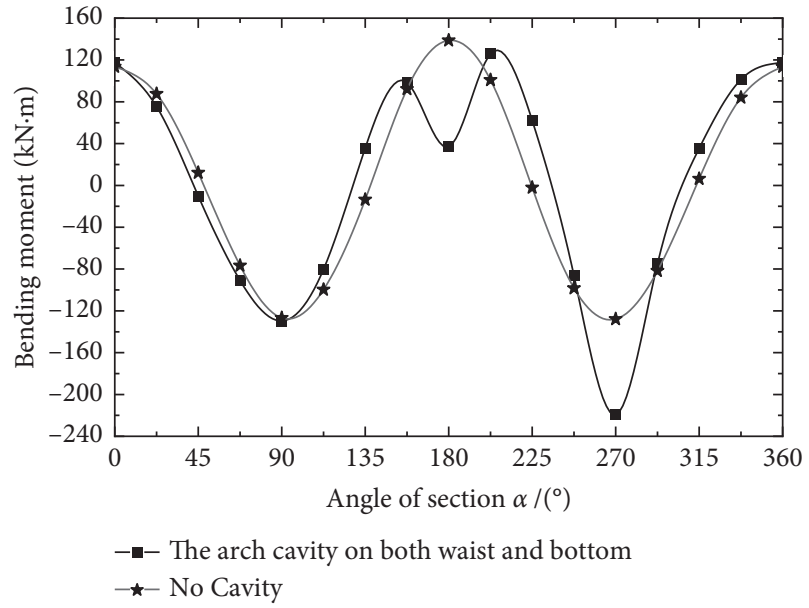

(b)

FIGURE 24: Internal force diagram of the cavity behind the arch waist and arch bottom. (a) Segment axial force. (b) Segment bending moment.

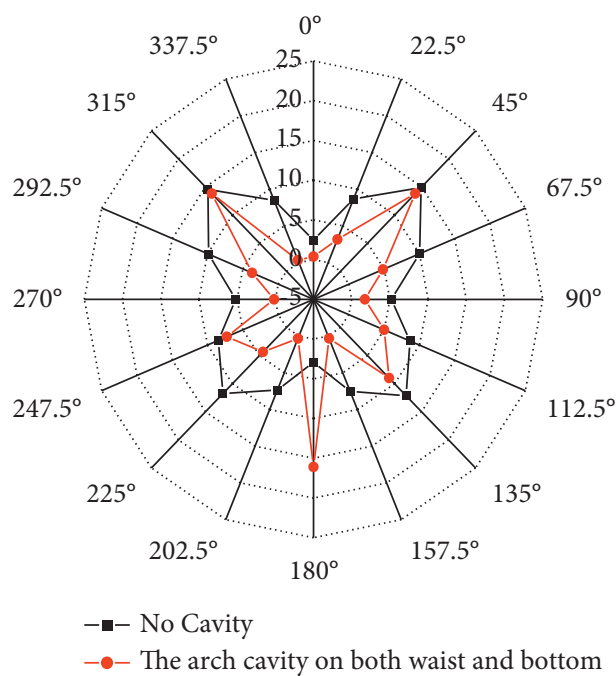

Figure 25: Safety coefficient of the segment cross section of arch waist and cavity behind the arch bottom. 


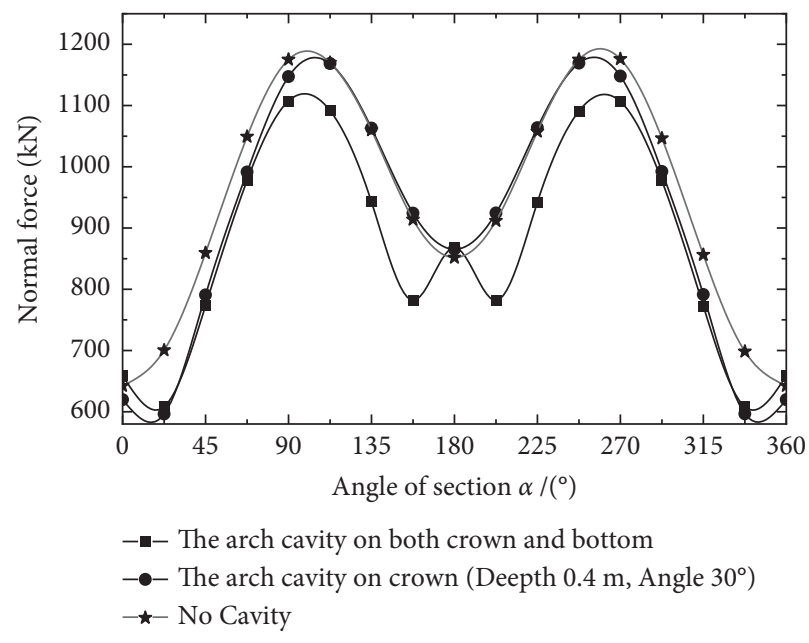

(a)

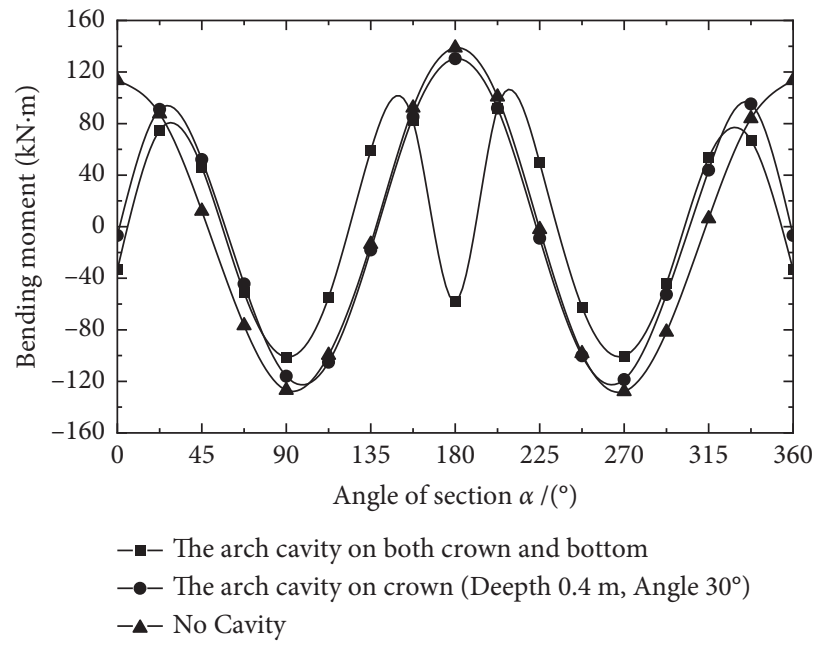

(b)

FIgURE 26: Internal force diagram of the cavity behind the arch waist and arch bottom. (a) Segment axial force. (b) Segment bending moment.

bending moment distribution law of the segment changes significantly compared with that of the noncavity condition. The bending moment values at the top and bottom of the arch are reversed, and the cross section is changed from positive bending to negative bending, and the bending moment values of the adjacent cross section on both sides increase significantly. Compared with the single cavity condition ( $30^{\circ}$ angle behind the vault, $0.4 \mathrm{~m}$ deep cavity), the existence of multiple cavities intensifies the influence of a single cavity on the segment, the bending moment value of the vault of the segment in this condition is reversed, the bending moment value becomes negative, and the bending moment value of the vault increases by $22.53 \%$ compared with the single cavity condition ( $30^{\circ}$ angle behind the vault, $0.4 \mathrm{~m}$ deep cavity). Due to the existence of the cavity behind the vault and the arch base, the safety coefficient at the vault, arch base, and both sides of the arch waist section increases compared with that without the cavity, and the safety coefficients at $45^{\circ}, 135^{\circ}, 225^{\circ}$, and $315^{\circ}$ section locations are reduced, as shown in Figure 27.

4.2. Numerical Simulation Analysis of the Effect of ThreeCavity Combinations. Three sets of three-cavity combination conditions were set up for finite element modeling calculation to analyze the axial force and bending moment distribution of shield tunnel lining under different cavity combinations, and the schematic diagram of each condition is shown in Figure 28.

4.2.1. Double-Sided Arch Waist and Cavity behind the Vault. As shown in Figure 29, the bending moment at the top of the vault decreases compared with that without the cavity when there is a cavity behind the vault on both sides of the segment. Compared with the cavity behind the arch waist on both sides, the maximum value of bending moment under this condition is smaller than the maximum value of bending moment behind the arch waist on both sides due to the unloading effect of the upper part caused by the cavity behind the vault. The safety coefficient at the vault of the segment increases compared with that without the cavity, and the safety coefficients at other cross-sectional positions reduce to a certain extent, among which the larger sections mainly appear at both sides of the vault waist and both sides of the vault, as shown in Figure 30.

4.2.2. Cavities behind the Vault, Arch Waist, and Arch Bottom. As shown in Figure 31, the bending moment values at the vault and bottom of the arch greatly reduce when there are cavities behind the vault, waist, and bottom of the arch. Unlike the case of the cavity behind the vault and arch, the bending moment values at the vault and arch bottom are not reversed in this case and tend to zero, the distribution of bending moment values of the segment is tilted to the left side of the arch waist, and the maximum bending moment of the segment appears at the position of the corresponding section of the cavity behind the arch waist. The safety coefficient of the bottom of the segment increases greatly compared with that without the cavity, while the safety coefficients of the left arch waist, arch vault, and arch bottom sections decrease among which the left arch waist has the largest decrease, as shown in Figure 32.

4.2.3. Cavities behind the Arch Waist and Arch Bottom on Both Sides. As shown in Figure 33, when there is a cavity behind both sides of the arch waist and arch bottom, the force law of the segment is similar to that of the cavity behind both sides of the arch waist and arch vault, the bending moment value at both sides of the arch waist increases compared with that without a cavity, the bending moment value at the arch bottom decreases significantly, and the original load of the section is mainly shared by both sides of 


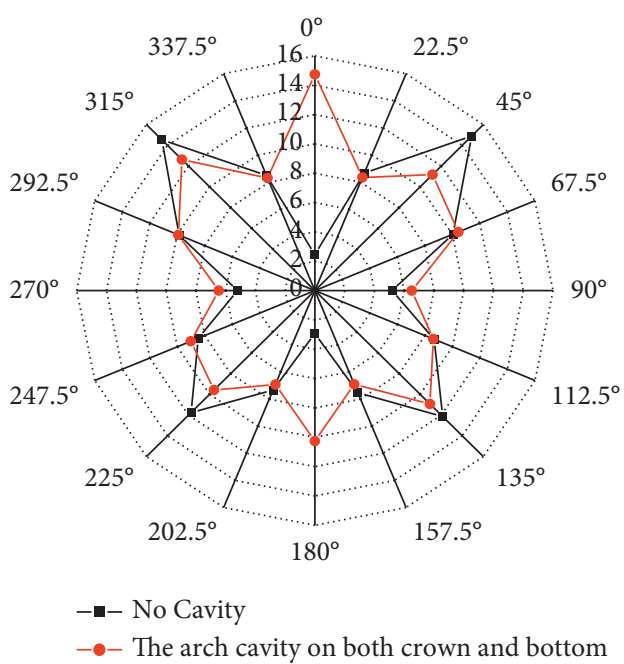

Figure 27: Safety coefficient of the segment cross section of arch waist and cavity behind the arch bottom.

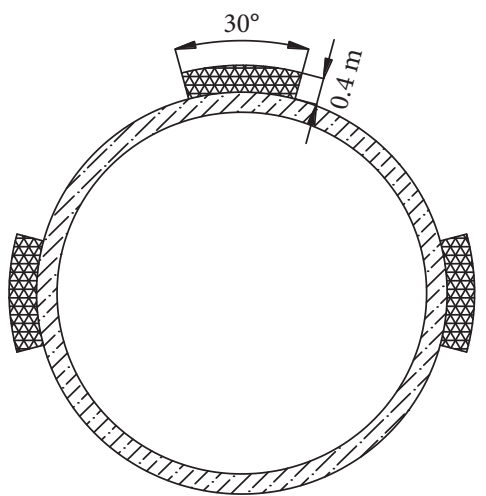

(a)

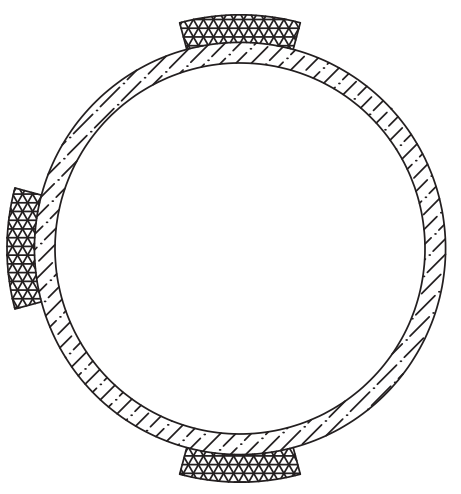

(b)

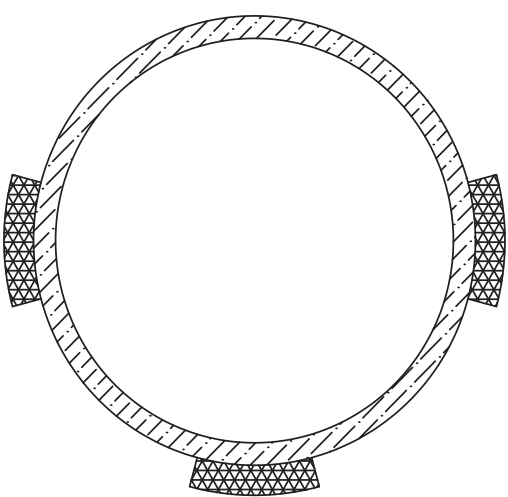

(c)

Figure 28: Combined working conditions of three cavities. (a) Double-sided arch waist and behind the arch roof cavity. (b) Arch roof, arch waist, and behind the arch bottom cavity. (c) Double-side arch waist and behind the arch bottom cavity.

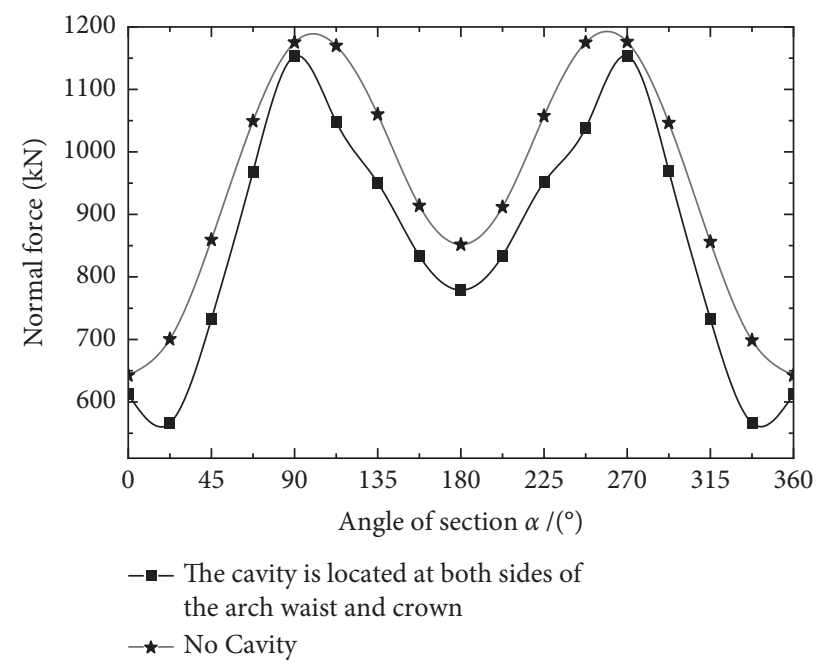

(a)

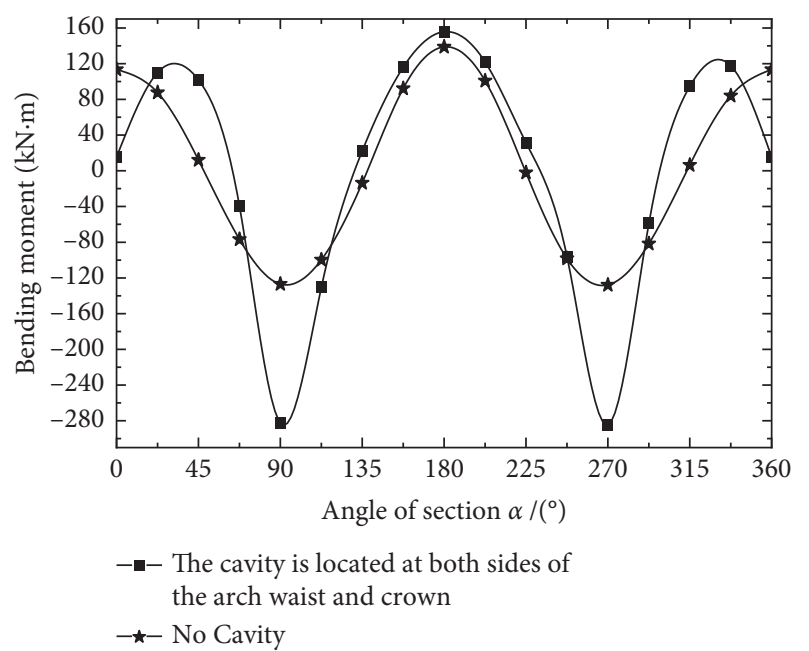

(b)

Figure 29: Internal force diagram of the cavity behind the arch waist and vault on both sides. (a) Segment axial force. (b) Segment bending moment. 


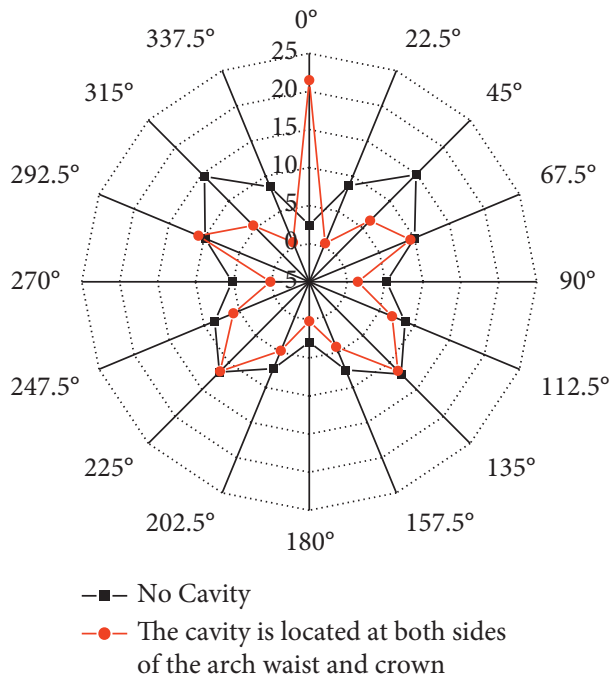

Figure 30: Safety coefficient of the segment cross section of the cavity behind the bilateral arch waist and vault.

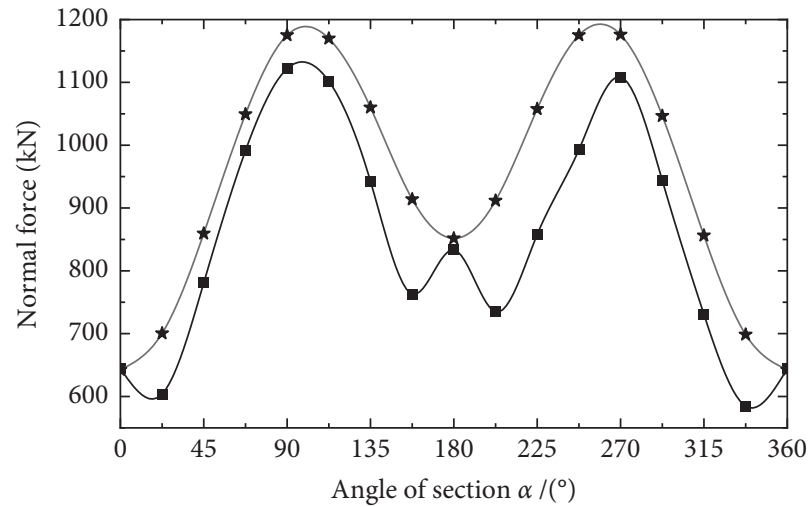

- - The cavity is located at the crown, arch waist and arch bottom

$-\star-$ No Cavity

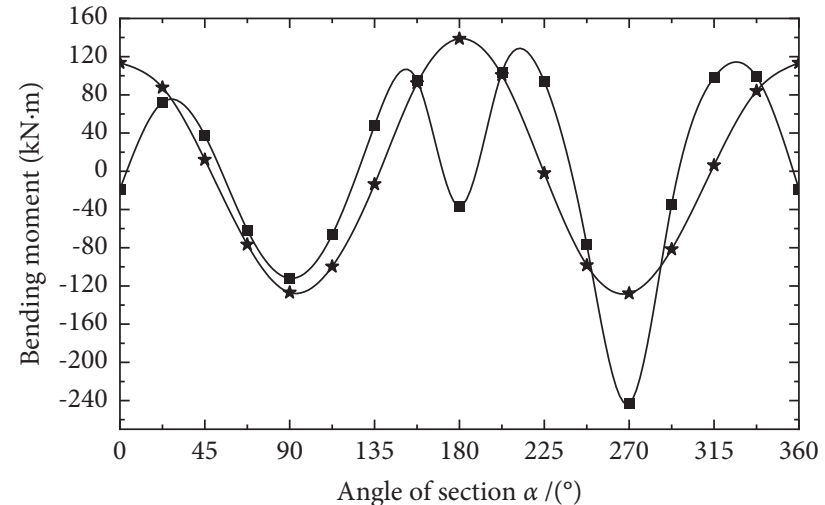

- The cavity is located at the crown, arch waist and arch bottom

$-\star-$ No Cavity

(a)

(b)

FIgURe 31: Internal force diagram of the vault top, arch waist, and cavity behind the arch bottom. (a) Segment axial force. (b) Segment bending moment.

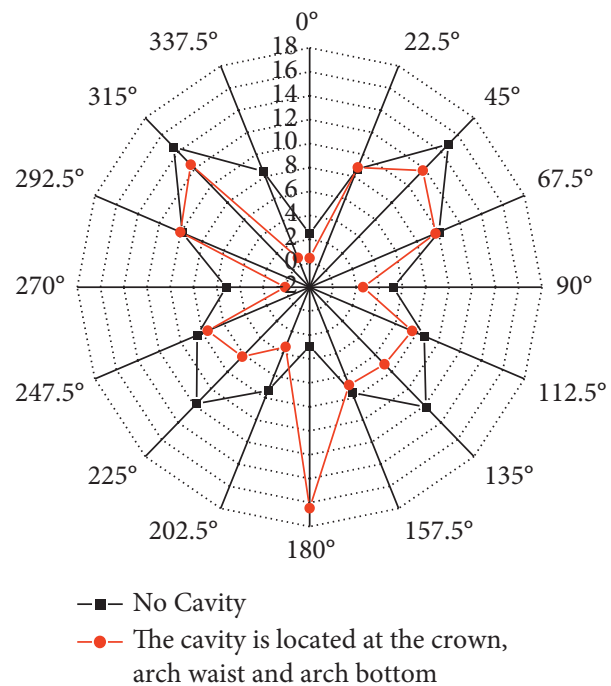

Figure 32: Coefficient of the safety of vault, arch waist, and cavity tube section behind the arch bottom. 


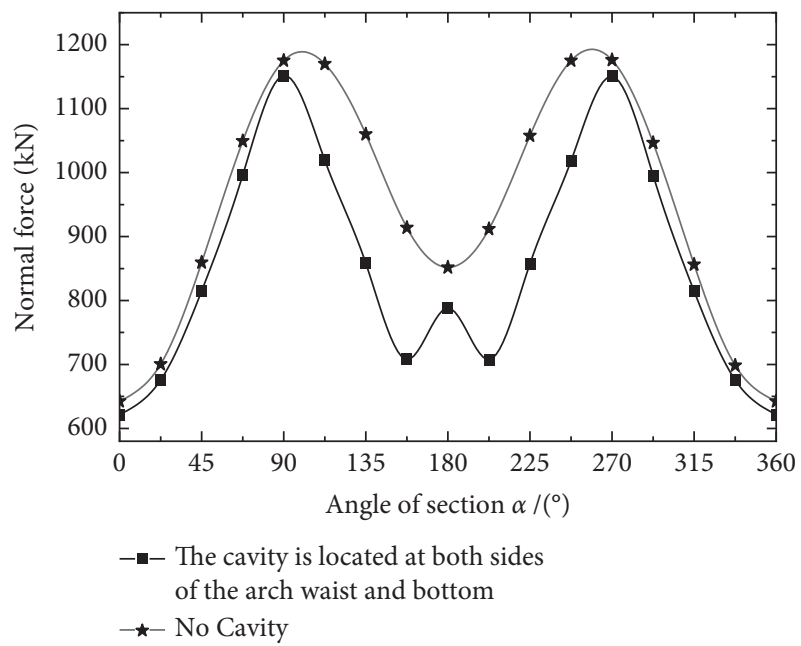

(a)

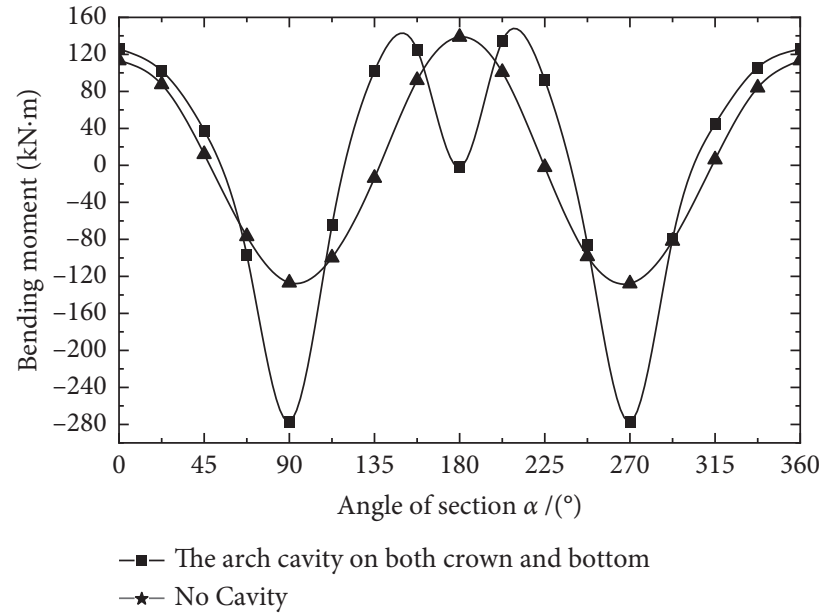

(b)

Figure 33: Internal force diagram of the segment under the condition of the cavity at both sides of the arch waist and arch bottom. (a) Segment axial force. (b) Segment bending moment.

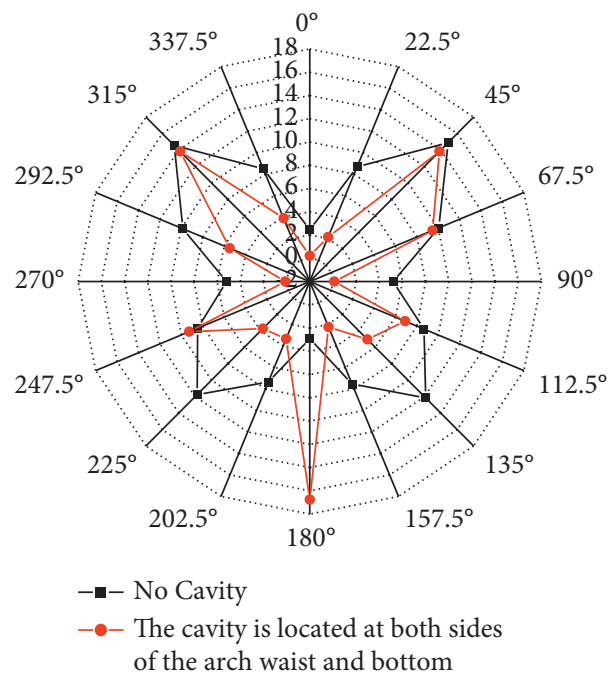

FIGURE 34: Safety coefficient of the segment cross section under the condition of the cavity at both sides of the arch waist and arch bottom.

the section so that the bending moment at both sides of the adjacent section increases significantly. Under this condition, the safety coefficient at the bottom of the arch increases significantly compared with that without a cavity, while the safety coefficients at both sides of the arch waist and both sides of the arch bottom sections decrease significantly, as shown in Figure 34.

The results of the analysis in Section 4 of this paper are also consistent with the conclusions of similar literature $[26,27]$. Namely, the safety coefficient of each section of the tunnel segment between multiple cavities is significantly lower than that without cavities and shows a tendency to decrease gradually with the increase of cavity size. The existence of multiple cavities intensifies the influence of each cavity on the segment, especially when there are cavities behind the top and bottom of the vault.

\section{Conclusion}

(1) The existence of the cavity changes the contact state between the tunnel and the surrounding strata, which in turn causes a redistribution of stress in the tunnel segment when the shield tunnel lining is behind a single cavity state:

(a) With the increase of the single cavity angle, the range of the affected section of the segment increases gradually, the value of the axial force and bending moment at vault arch decreases, and the bending moment value and the cavity angle value are approximately linear; when the angle of the cavity behind the arch is greater than 
$30^{\circ}$, the bending moment at the vault arch is reversed.

(b) With the increase of single cavity depth, the axial force and bending moment at the cavity increase, and the bending moment tends to be stable and unchanged beyond a certain depth.

(c) With the increase of single cavity angle and depth, the structural safety coefficient of the segment decreases, and the degree of influence is angle value $>$ depth value.

(2) Under the combination of multiple cavities, the shield tunnel segment is subjected to more serious bias than the single cavity, the force pattern is more complex, the overall safety of the structure decreases significantly, and the force law of the segment is similar to that of the single cavity.

(3) The existence of multiple cavities intensifies the influence of each cavity on the segment, especially when there are cavities behind the top and bottom of the vault; the bending moment value of the top of the vault increases by $22.53 \%$ compared with that of the single cavity condition.

(4) The effects of stiffness reduction at the tunnel segment joints and groundwater seepage are not considered in this paper; the mechanical values and laws of the shield tunnel model will produce certain errors, whose effects can be further considered subsequently.

(5) This paper only considers three typical section position conditions of the vault, arch waist, and arch bottom, which are not fixed in the actual project due to various factors. The influence of cavities in other locations on tunnel segments can be explored by further encrypting the condition.

\section{Data Availability}

Some or all data, models, or codes that support the findings of this study are available from the corresponding author upon reasonable request.

\section{Conflicts of Interest}

The authors declare that they have no conflicts of interest.

\section{Authors' Contributions}

Yufeng Shi developed the research program and contributed to the administration, supervision, funding acquisition, investigation, writing the original draft, and reviewing and editing of the manuscript. Zhaoyang Chen contributed to the formal analysis, design model experiments, methodology, data processing, and reviewing and editing of the manuscript. Duqiang Wei contributed to the numerical simulation, validation, data processing, and reviewing and editing of the manuscript. Tao Zhang participated in model experiments and numerical simulation, validation, and reviewing and editing of the manuscript. Xuming Zhou provides research ideas and technical guidance and contributed to the reviewing and editing of the manuscript. Xiushao Zhao provides research support and contributed to the methodology and reviewing and editing of the manuscript. Junhao $\mathrm{Hu}$ participated in the numerical simulation and model test and the reviewing and editing of the manuscript. Yuhang Zhou participated in model experiments, translation, and the reviewing and editing of the manuscript.

\section{Acknowledgments}

The authors wish to acknowledge the financial support from the National Natural Science Foundation of China (Grant no. 42177162) and National Regional Science Foundation of China (Grant no. 51768020).

\section{References}

[1] D. Zhang, S. Zhang, F. Qian, and F. Chen, "Contact state behind lining of railway operation tunnel and its analysis," Journal of rock mechanics and engineering, vol. 32, no. 2, pp. 217-224, 2013.

[2] W. Wang, L. Gao, H. Zhang, and J. Deng, "Influence of double cavities behind masonry lining on tunnel structure safety," Highway traffic science and technology, vol. 35, no. 5, pp. 82-90, 2018.

[3] W. Yang, M. Bo, S. Zhang, G. Ying, and J. Fang, "Study on the causes and laws of cavities behind highway tunnel lining," Highway traffic science and Technology (Application Technology Edition), vol. 10, no. 2, pp. 153-154, 2014.

[4] W. G. Friebel, Dr. lng, and J. Krieger, "Quality assurance and assessing the state of road tunnel using non-destructive test methods," Quality Assurance, pp. 31-34, 2010.

[5] F. Huang, X. Liu, J. Chen, H. Cheng, and Z. Lin, "Model test study on influence of cavity behind lining on tunnel structure safety," Journal of Chongqing Jianzhu University, vol. 39, no. 3, pp. 69-77, 2020.

[6] M. A. Meguid and H. K. Dang, "The effect of erosion voids on existing tunnel linings," Tunnelling and Underground Space Technology, vol. 24, no. 3, pp. 278-286, 2009.

[7] C. Leung and M. A. Meguid, "An experimental study of the effect of local contact loss on the earth pressure distribution on existing tunnel linings," Tunnelling and Underground Space Technology, vol. 26, no. 1, pp. 139-145, 2011.

[8] S. Wang, P. Wang, Yu Liu, and B. Zhu, "Experimental study on failure modes of tunnels with cavities at different locations," Journal of Northeastern University, vol. 41, no. 6, pp. 863-869, 2020.

[9] S. Wang, Q. Yu, Bo Peng, and X. Shen, "Model test study on the influence of cavity on the stress and failure of shield tunnel structure," Geotechnical Engineering Journal, vol. 39, no. 1, pp. 89-98, 2017.

[10] Y. Shi, Q. Fu, J. Zhuang, and S. Peng, "Study on influence of connection weakening between invert and side wall of pressure tunnel on support characteristics," Jiangxi water conservancy science and technology, vol. 44, no. 1, pp. 9-14, 2018.

[11] Y. Shi, Q. Fu, J. Gao, and H. Zhang, "Analysis on the influence of void area on lining internal force of hydraulic pressure tunnel," Jiangxi water conservancy science and technology, vol. 42, no. 3, pp. 157-161, 2016.

[12] J. Ding, B. Liu, Z. Mo et al., "Study on influence of surrounding rock cavity distribution on mechanical properties of tunnel lining structure," Journal of Nanjing Institute of 
Engineering (Natural Science Edition), vol. 17, no. 2, pp. 2528, 2019.

[13] Z. Li, D. Li, and F. Peng, "Analysis of the influence of multiple cavities behind the Shanling tunnel on lining structure," Journal of Railway Science and Engineering, vol. 13, no. 1, pp. 138-145, 2016.

[14] Y. Deng, Y. Yilmaz, A. Gokce, and C. S. Ching, "Influence of particle size on the drained shear behavior of a dense fluvial sand," Acta Geotechnica, vol. 16, 2021, prepublish.

[15] T. Zhao, L. Wen, and Z. Ye, "Effects of water inrush from tunnel excavation face on the deformation and mechanical performance of shield tunnel segment joints," Civil Structures, vol. 2017, 2018

[16] D. Wu, K. Xu, P. Guo et al., "Ground deformation characteristics induced by mechanized shield twin tunnelling along curved alignments," Advances in Civil Engineering, vol. 2021, Article ID 5913640, 18 pages, 2021.

[17] M. Reza Majedi, M. Afrazi, and F. Ali, "A micromechanical model for simulation of rock failure under high strain rate loading," International Journal of Civil Engineering, 2020, prepublish.

[18] R. Salman, A. Mohammad, F. Ali, and Y. Mahmoud, "Strength and deformation behaviour of sand-rubber mixture," International Journal of Geotechnical Engineering, vol. 15, no. 9, 2021.

[19] X. Li, S. Zhou, H. Di, and T. Saksala, "Observed ground pressure acting on the lining of a large-diameter shield tunnel in sandy stratum under high water pressure," Advances in Civil Engineering, vol. 2020, Article ID 3091528, 12 pages, 2020.

[20] M. Lei, D. Lin, C. Shi, J. Ma, W. Yang, and J. Sun, “A structural calculation model of shield tunnel segment: heterogeneous equivalent beam model," Advances in Civil Engineering, vol. 2018, 2018.

[21] GB/T 50123, Standard for Soil Test Methods [S], 2019.

[22] D. Huang, X. Li, and C. Han, Measuring Device and Method for Radial Bending Modulus of Elasticity of Ring, CN, Shanghai, China, 2014.

[23] A. K. Alzo'Ubi, “The role OF block ratio and layer thickness ON rock slopes movement style," International Journal of Geomate Geotechnique Construction Materials \& Environment, vol. 8, no. 2, pp. 1271-1277, 2015.

[24] A. K. Alzo'Ubi, Effect Of Strength Properties On Displacement Magnitude And Fracturing Amount Inside A Large Open Pit Prone To Toppling, 2019.

[25] A. Alzo'Ubi, "Modeling yield propagation of jointed synthetic rock," in Proceedings of the 2016 Isrm International Symposium, Eurock 2016, Cappadocia, Turkey, July 2016.

[26] J. Ye, Structural Design Principle, People's Communications Press, Beijing, China, 2012.

[27] Industry Standard Compilation Group of the People's Republic of China, JTG 3370.1-2018, Code for Design of Highway Tunnels Volume I, Civil Engineering, People's Communications Press, Beijing, China, 2018.

[28] M. Q. Xiao and X. Chen, "Modification and application of total safety factor design method for composite lining tunnel," Tunnel construction (Chinese and English), vol. 39, no. 3, pp. 421-429, 2019.

[29] Xu Zhang, C.-ping Zhang, G. Feng, and K.-hang Han, "Experimental studies on effect of voids behind tunnel linings on progressive failure process of tunnel structures," Journal of Geotechnical Engineering, vol. 39, no. 6, pp. 1137-1144, 2017.

[30] C.-p. Zhang, G. Feng, X. Zhang, K.-h. Han, and D.-1. Zhang, "Effect of double voids behind lining on safety state of tunnel structures," Journal of Geotechnical Engineering, vol. 37, no. 3, pp. 487-493, 2015. 